\title{
Diagnosability performance analysis of models and fault detectors
}

\author{
Daniel Jung
}

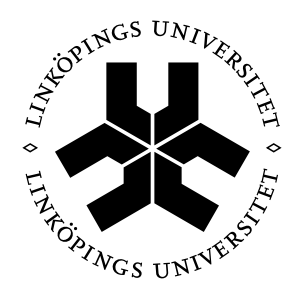

\section{Linköpings universitet INSTITUTE OF TECHNOLOGY}

Department of Electrical Engineering

Linköping University

SE-581 83 Linköping, Sweden

Linköping 2015 
Linköping studies in science and technology. Dissertations, No. 1660

Diagnosability performance analysis of models and fault detectors

Daniel Jung

ISBN 978-91-7519-080-8

ISSN 0345-7524

(C) 2015 Daniel Jung, unless otherwise noted. All rights reserved.

Daniel Jung

daniel.jung@liu.se

www.vehicular.isy.liu.se

Division of Vehicular Systems

Department of Electrical Engineering

Linköping University

SE-581 83 Linköping

Sweden

The cover: Graphical illustration of the proposed quantitative fault detectability and isolability performance measure, called distinguishability $\left(\mathcal{D}_{i, j}(\theta)\right)$.

Typeset with $\operatorname{AT} \mathrm{TEX}_{\mathrm{E}} 2 \varepsilon$

Printed by LiU-Tryck, Linköping, Sweden 2015 
To Ylva 



\section{Abstract}

Model-based diagnosis compares observations from a system with predictions using a mathematical model to detect and isolate faulty components. Analyzing which faults that can be detected and isolated given the model gives useful information when designing a diagnosis system. This information can be used, for example, to determine which residual generators can be generated or to select a sufficient set of sensors that can be used to detect and isolate the faults. With more information about the system taken into consideration during such an analysis, more accurate estimations can be computed of how good fault detectability and isolability that can be achieved.

Model uncertainties and measurement noise are the main reasons for reduced fault detection and isolation performance and can make it difficult to design a diagnosis system that fulfills given performance requirements. By taking information about different uncertainties into consideration early in the development process of a diagnosis system, it is possible to predict how good performance can be achieved by a diagnosis system and avoid bad design choices. This thesis deals with quantitative analysis of fault detectability and isolability performance when taking model uncertainties and measurement noise into consideration. The goal is to analyze fault detectability and isolability performance given a mathematical model of the monitored system before a diagnosis system is developed.

A quantitative measure of fault detectability and isolability performance for a given model, called distinguishability, is proposed based on the Kullback-Leibler divergence. The distinguishability measure answers questions like "How difficult is it to isolate a fault $f_{i}$ from another fault $f_{j}$ ?". Different properties of the distinguishability measure are analyzed. It is shown for example, that for linear descriptor models with Gaussian noise, distinguishability gives an upper limit for the fault to noise ratio of any linear residual generator. The proposed measure is used for quantitative analysis of a nonlinear mean value model of gas flows in a heavy-duty diesel engine to analyze how fault diagnosability performance varies for different operating points. It is also used to formulate the sensor selection problem, i.e., to find a cheapest set of available sensors that should be used in a system to achieve required fault diagnosability performance.

As a case study, quantitative fault diagnosability analysis is used during the design of an engine misfire detection algorithm based on the crankshaft angular velocity measured at the flywheel. Decisions during the development of the misfire detection algorithm are motivated using quantitative analysis of the misfire detectability performance showing, for example, varying detection performance at different operating points and for different cylinders to identify when it is more difficult to detect misfires.

This thesis presents a framework for quantitative fault detectability and isolability analysis that is a useful tool during the design of a diagnosis system. The different applications show examples of how quantitate analysis can be applied during a design process either as feedback to an engineer or when formulating different design steps as optimization problems to assure that required performance can be achieved. 


\section{Populärvetenskaplig sammanfattning}

Vårt samhälle är beroende av många avancerade tekniska system där ett fel i något av dessa system kan leda till allvarliga konsekvenser och resultera i att människor skadas, miljöskadliga utsläpp, dyra reparationskostnader eller ekonomiska förluster på grund av oväntade produktionsstopp. Diagnossystem för att övervaka sådana tekniska system är därför viktiga för att kunna identifiera när ett fel inträffar så att lämpliga åtgärder kan vidtas innan något allvarligt hinner hända. Ett diagnossystem använder mätsignaler från systemet som ska övervakas för att upptäcka om fel har uppstått i en komponent och beräknar sedan möjliga förklaringar på vilka fel som kan finnas i systemet.

I modellbaserad diagnos används metoder där en matematisk modell som beskriver systemet används för att upptäcka (detektera) och peka ut (isolera) en felande komponent genom att jämföra mätsignaler med förväntat beteende givet modellen. Osäkerheter i modellen, mätbrus och var sensorer är placerade i systemet begränsar möjligheten att detektera och isolera olika fel med ett diagnossystem. Med hjälp av kunskap om osäkerheter, och var sensorer kan

placeras, kan ett diagnossystem konstrueras så att den negativa påverkan av osäkerheterna begränsas.

I denna avhandling analyseras hur bra feldetektions- och felisoleringsprestanda som kan uppnås givet en matematisk modell av systemet som ska övervakas. Diagnosprestanda analyseras kvantitativt genom att ta hänsyn till osäkerheterna i modellen, mätbrus och hur varje fel ser ut. Ett mått för att analysera kvantifierad diagnosprestanda för en given modell presenteras och exempel visar hur detta mått kan användas för att analysera diagnosegenskaper där modellosäkerheter och mätbrus är kända. Olika egenskaper hos måttet analyseras, till exempel kopplingen till diagnosprestanda och hur diagnosprestanda ändras om mängden tillgänglig data ökar. Olika tillämpningar som analyseras i detta arbete är till exempel kvantitativ analys av diagnosprestanda givet en model av en dieselmotor samt att hitta en billigaste uppsättning sensorer som uppfyller önskad diagnosprestanda.

Slutligen tillämpas kvantitativ diagnosanalys på ett verkligt problem inom fordonsindustrin som handlar om detektion av misständningar i bensinmotorer. Misständning sker i en cylinder exempelvis på grund av ett trasigt tändstift och orsakar skador på katalysatorn med förhöjda avgasutsläpp till följd. Ett diagnossystem har utvecklats för att detektera när en misständning inträffar utifrån varvtalsmätningar på motorns svänghjul. Kvantitativ analys av diagnosprestandan har använts under utvecklingen av algoritmen för att motivera olika designval som förbättrar diagnosprestandan.

Metoderna som presenteras i denna avhandling är användbara verktyg för att kvantitativt utvärdera diagnosprestanda tidigt i designprocessen. Tillämpningarna som analyserats i avhandlingen ger exempel på hur metoderna kan användas under utvecklingen av ett diagnossystem. Exempel på detta är som analysverktyg för en ingenjör för se vilka designval som bäst förbättrar prestandan eller för att formulera optimeringsproblem där lösningen ska uppfylla önskade prestandakrav. 


\section{Acknowledgment}

This work has been carried out at the Division of Vehicular Systems at the Department of Electrical Engineering, Linköping University.

Many things have happened during these last five years and there are many people I want to thank for making this thesis a reality. First of all I would like to express my gratitude to my supervisor Dr. Erik Frisk and co-supervisor Dr. Mattias Krysander for all guidance and inspiration that you have given me during these five years. I have always been able to ask you for advice and I appreciate our interesting discussions and your insightful inputs that have helped me write this thesis.

I want to thank Prof. Lars Nielsen for letting me join his research group. I also want to thank all of my colleagues for the nice and relaxed atmosphere, all fun and interesting discussions, but also the joy when being at work. I want to acknowledge Dr. Lars Eriksson for all your support during the work with the misfire project and Dr. Jan Åslund for the help with the asymptotic analysis. I also want to thank Maria Hamnér and Maria Hoffstedt for all help with administrational issues.

I want to thank Prof. Gautam Biswas and his students Hamed Khorasgani, Joshua Carl, and Yi Dong for a great time and hospitality during my visit at Vanderbilt University. I really enjoyed the time in Nashville and our interesting discussions have really taught me a lot. I hope that I can come back and visit you again soon.

I also want to acknowledge Dr. Sasa Trajkovic and his co-workers at Volvo Cars in Torslanda for all help during the work with the misfire detection project. It has been fun to work in this project and I appreciate all useful inputs and help with data collection during my visits.

I want to thank Lic. Ylva Jung and Sergii Voronov for proofreading parts of the manuscript. The number of typos would never be this few if it wasn't for you.

I will forever be in dept to my parents Bonita and Mats and my brother Mikael, for all your support. If it was not for you I would not have been here today. I also want to thank all of my friends that bring my life much joy and happiness.

Last but not least, I want to express my deep gratitude and love to my wife Ylva Jung for all her support, joy, encouragement, patience, and for being with me when I need you the most. I hope that this journey together with you will never end.

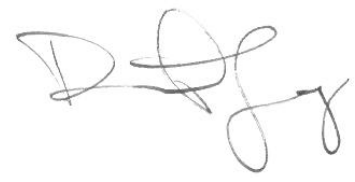




\section{Contents}

1 Introduction $\quad 3$

1.1 Fault diagnosis . . . . . . . . . . . . . . . . 5

1.2 Motivation for quantitative fault diagnosability analysis . . . . . . . . 9

1.3 Research topic . . . . . . . . . . . . . . . . . . . . . . . . 10

1.4 Contributions . . . . . . . . . . . . . . . . . . . . 12

1.5 Concluding remarks and future work . . . . . . . . . . . . . . 14

1.6 Publications . . . . . . . . . . . . . . . . . 15

2 Performance analysis in model based diagnosis $\quad 17$

2.1 Diagnosability analysis of uncertain systems . . . . . . . . . . . . . 17

2.2 Design aspects of diagnosis systems . . . . . . . . . . . . . . 23

3 Engine misfire detection performance analysis $\quad \mathbf{2 5}$

3.1 Approaches to engine misfire detection . . . . . . . . . . . 26

3.2 Misfire detection based on crankshaft angular velocity measurements . 26

3.3 Quantitative analysis of misfire detection performance . . . . . . . 28

References 33

$\begin{array}{ll}\text { Papers } & 41\end{array}$

1 A method for quantitative fault diagnosability analysis of stochastic linear descriptor models $\quad 43$

1 Introduction . . . . . . . . . . . . . . . . . . 45

2 Problem formulation . . . . . . . . . . . . . . . 46

3 Distinguishability . . . . . . . . . . . . . . . . . 47

4 Computation of distinguishability . . . . . . . . . . . . . 53 
5 Relation to residual generators . . . . . . . . . . . . . 57

6 Diesel engine model analysis . . . . . . . . . . . . . . . . . . . 60

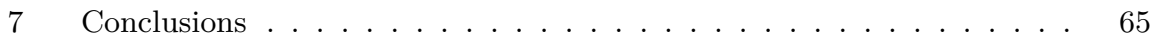

References . . . . . . . . . . . . . . . . . . 67

2 Asymptotic behavior of fault diagnosis performance $\quad 71$

1 Introduction . . . . . . . . . . . . . . . . . . . . . 73

2 Problem formulation . . . . . . . . . . . . . . . . 74

3 Background . . . . . . . . . . . . . . . . 76

4 Asymptotic detectability performance . . . . . . . . . . . . 81

5 Asymptotic isolability performance . . . . . . . . . . . . . . 96

6 Conclusions . . . . . . . . . . . . . . . . . . 103

References . . . . . . . . . . . . . . . . . . . . 104

3 Quantitative isolability analysis of different fault modes 107

1 Introduction . . . . . . . . . . . . . . . . . . . . . . . . 109

2 Problem formulation . . . . . . . . . . . . . . . . . 110

3 Background . . . . . . . . . . . . . . . . . . . . . 112

4 Representing fault modes using probabilities of fault time profiles . . . 114

5 Candidate measures of distinguishability between fault modes . . . . . 115

6 Discussion . . . . . . . . . . . . . . . . . . . 120

$7 \quad$ Computation of expected distinguishability . . . . . . . . . . . . . 121

8 Case study . . . . . . . . . . . . . . . . . . . . . . . . 122

9 Conclusions . . . . . . . . . . . . . . . . . . . 125

References . . . . . . . . . . . . . . . . . 126

4 Sensor selection for fault diagnosis in uncertain systems $\quad \mathbf{1 2 9}$

1 Introduction . . . . . . . . . . . . . . . . . . . . . . . . . . . 131

2 Problem statement . . . . . . . . . . . . . . . . . . . 132

3 Theoretical background . . . . . . . . . . . . . . . . 133

4 Analysis . . . . . . . . . . . . . . . . . . . 137

5 Sensor placement algorithms . . . . . . . . . . . . . . 141

$6 \quad$ Case study . . . . . . . . . . . . . . . . . . . . . . . . 145

$7 \quad$ Conclusions . . . . . . . . . . . . . . . . . . . 150

References . . . . . . . . . . . . . . . . . 152

5 Development of misfire detection algorithm using quantitative FDI performance analysis $\quad 155$

1 Introduction . . . . . . . . . . . . . . . . . . 157

2 Problem formulation . . . . . . . . . . . . . . . . . . 158

3 Engine crankshaft model . . . . . . . . . . . . . . . . . . . 161

4 Misfire detectability analysis . . . . . . . . . . . . . . . 165

5 Design of misfire detection algorithm . . . . . . . . . . . . . 175

6 Evaluation . . . . . . . . . . . . . . . . . . . . 180

7 Conclusions . . . . . . . . . . . . . . . . . . . . . . 187

References . . . . . . . . . . . . . . . . . . . 188 
6 A flywheel manufacturing error compensation algorithm for engine $\begin{array}{lr}\text { misfire detection } & 191\end{array}$

1 Introduction . . . . . . . . . . . . . . . . . . . . . . 193

2 Available data from vehicles on the road . . . . . . . . . . . . 195

3 Misfire detection algorithm . . . . . . . . . . . . . . . . 197

4 Modeling of flywheel tooth angle errors . . . . . . . . . . . . . . 199

5 Estimating flywheel tooth angle errors . . . . . . . . . . . . . . . 201

$6 \quad$ Evaluation of misfire detection algorithm with flywheel error comp ... . 212

7 Conclusions . . . . . . . . . . . . . . . . 216

References . . . . . . . . . . . . . . . . . . . . . 218 



\section{Introduction}





\section{Introduction}

Unexpected behavior and failures in technical systems are often problematic and sometimes also dangerous. The ability to identify a degraded or damaged component early, and hopefully before its functionality is lost, is important to assure the system's reliability and availability. A diagnosis system is used to monitor the system's health and identify occurred faults. Information about detected faults can be used to select suitable counter measures, such as scheduled maintenance, updated mission planning, or on-line fault adaptation.

Diagnosis systems are designed around the basic idea of comparing measured system behavior with predicted behavior. If a fault affects the system behavior in a way that is not captured by the predictions it is possible to detect the discrepancy. The goal is then to detect these differences between measurements and the predictions and identify the faults. The predictions are based on knowledge about the system, for example, previous measurements, mathematical models, expert user experience, etc., see Figure 1.1. The main approach considered in this thesis is fault diagnosis based on the use of mathematical models, which is usually referred to as model-based diagnosis.

Design of a diagnosis system can be a difficult task. If the available knowledge about the system is limited, for example if models are not accurate enough, it might only be possible to make rough estimates of the expected system behavior. This will make it difficult to detect relatively small faults because it is not possible to distinguish the effects of faults from prediction uncertainties. To be able to detect small faults the diagnosis system requires sufficiently accurate predictions of the system behavior and maybe more samples, i.e., longer time allowed for detection, in order to distinguish faulty from nominal behavior. Also, information about faults is usually limited since faults rarely occur and often after long usage-time. Thus, including fault models in the system model is sometimes necessary to understand how different faults will affect the system to 


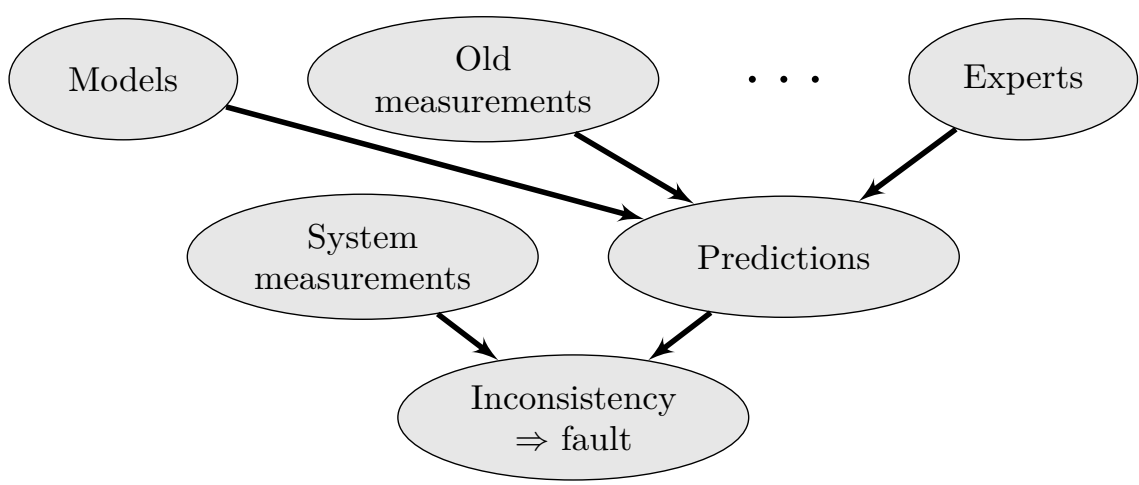

Figure 1.1: Diagnosis systems compares predicted system behavior with observations to detect inconsistencies. The predictions can be based on, for example, models, old measurements, expert knowledge, or combinations of these.

be able to correctly identify the true fault. Again, model quality is important since a more accurate model will give a better understanding about the fault propagation.

There might be many candidate signals comparing measurements with predictions, for example, residuals, that can be used to detect a fault. However, because of the model quality and measurement noise, the ability to detect a fault can vary between different candidates which can have a huge impact on detectability performance. As an example, two residuals, $r_{1}(t)$ and $r_{2}(t)$, used to detect the same fault are shown in Figure 1.2. A fault occurs at time $t=500$ and the residual $r_{2}(t)$ deviates more when the fault occurs compared to $r_{1}(t)$. Even though both signals could be used to detect the fault, $r_{2}(t)$ in the right picture is better since the fault results in a larger deviation in the signal behavior. This type of qualitative comparison is useful in the diagnosis system design. However, a qualitative comparison does not tell if the better signal fulfills the diagnosability requirements. If diagnosability performance can be quantified, especially if it can be predicted early in the diagnosis system design process, it can be used to evaluate if required performance can be achieved before a diagnosis system has been developed.

An important research question, and the main topic of this thesis, in modelbased diagnosis is then to know if it is possible to predict achievable fault detectability and isolability performance by evaluating a model of the system. The negative impact on the performance of the diagnosis system is mainly caused by model uncertainties and measurement noise. If these negative effects can be estimated and quantified early in a design process, better design choices can be made in the diagnosis system design and engineering time can be saved. Evaluation of the model's ability to distinguish faulty from nominal system behavior can be used to predict achievable performance of a diagnosis system designed based on a model. If such an analysis indicates that sufficiently good diagnosability performance cannot be achieved by a diagnosis system, more work can be focused on, for example, improving models or adding more sensors, 

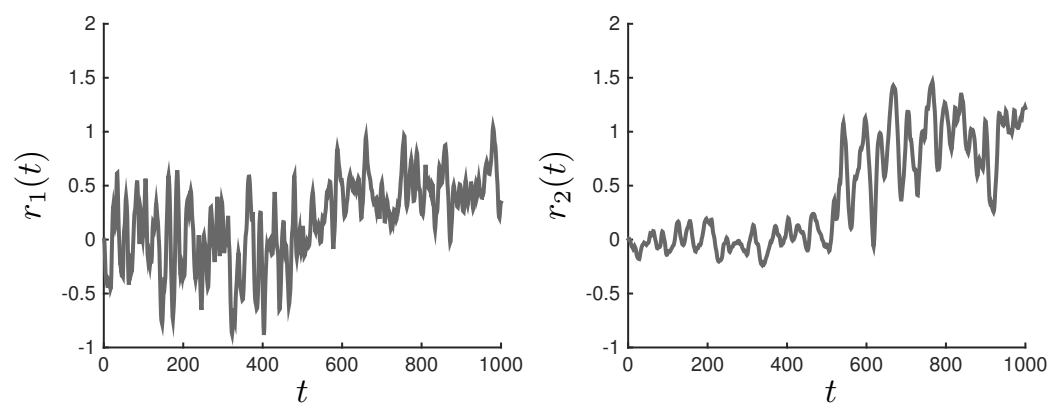

Figure 1.2: Two signals $r_{1}(t)$ and $r_{2}(t)$ computed to detect one type of fault. A fault occurs at time $t=500$ and the right signal deviates more when the fault occurs compared to the left which makes it a better candidate to detect the fault.

before putting a lot of work into developing a diagnosis system that will not fulfill the requirements. Quantitative analysis of diagnosability performance can be used, for example, to determine where to put sensors to best isolate faults, which parts of the model to use when designing residuals to achieve satisfactory performance, or understand during which operating conditions it is easier to detect faults.

A short introduction to model-based fault diagnosis is given in Section 1.1 before discussing the motivation of this thesis in Section 1.2. The research topic is discussed in Section 1.3, the contributions are described in Section 1.4, and some concluding remarks and future works in Section 1.5. Finally, a list of the publications written by the author of this thesis, including works not covered by this thesis, is presented in Section 1.6.

\subsection{Fault diagnosis}

Fault diagnosis research is conducted in many different research fields, such as control theory, artificial intelligence, and statistics. Interesting overviews can be found in, for example, (Hamscher et al., 1992; Venkatasubramanian et al., 2003a,b,c; Blanke et al., 2006) and (Qin, 2012).

Fault diagnosis mainly considers the three following problems, (Isermann and Balle, 1997; Ding, 2008)

- fault detection, which refers to detecting fault(s) present in the system,

- fault isolation, which refers to identifying which fault(s) that are present in the system, and

- fault identification, which refers to estimating the fault magnitudes and time-varying behavior.

A diagnosis system usually consists of a fault detection step, followed by a fault isolation step that is triggered when a fault is detected. Then, when a 
fault is isolated, an identification step is initiated to estimate the detected fault, see Figure 1.3. This thesis focuses on the first two problems, fault detection and isolation. A fault usually refers to an unpermitted deviation of one (or more) system parameters (Isermann and Balle, 1997). To denote a set of faults present in the system, of any fault realisation, the term fault mode is used. A diagnosis system here refers to an algorithm which takes observations from the system, usually sensor measurements, and computes diagnosis candidates. A diagnosis candidate is a statement about the current health state of the system that can explain the observed measurements, e.g., which faults that are present in the system (de Kleer and Williams, 1987). When considering both fault detectability and isolability performance, they will sometimes be referred to as fault diagnosability performance.

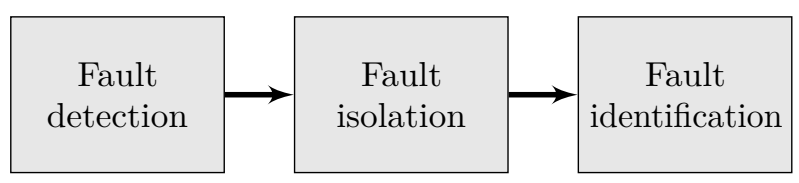

Figure 1.3: A general procedure of diagnosis systems.

\subsubsection{Model-based diagnosis}

In model-based diagnosis, system behavior predictions are computed based on a mathematical model of the system. The general principle of model-based diagnosis is then to compare measurements from the system with predictions of the model to detect inconsistencies. An inconsistency is the result of an unknown change in the system behavior, not explained by the model, and is then considered to be caused by a fault. Faults can then be included in the model based on how they will affect the system, for example, parameter changes or additive disturbances. As an example, a general model type is a state space model where faults are included as signals

$$
\begin{aligned}
\dot{x}(t) & =g(x(t), u(t), f(t), e(t)) \\
y(t) & =h(x(t), u(t), f(t), v(t))
\end{aligned}
$$

where $t$ is time index, $x(t) \in \mathbb{R}^{l_{x}}$ represents states, $u(t) \in \mathbb{R}^{l_{u}}$ are known actuator signals, $y(t) \in \mathbb{R}^{l_{y}}$ are sensor measurements, $f(t) \in \mathbb{R}^{l_{f}}$ are faults, and $e(t)$ and $v(t)$ are noise vectors, with zero mean and covariance matrices $Q \in \mathbb{R}^{l_{e} \times l_{e}}$ and $R \in \mathbb{R}^{l_{v} \times l_{v}}$, representing process noise and measurement noise respectively. The notation $l_{\alpha}$ denotes the number of elements in $\alpha$.

By computing predictions based on different parts of the model and comparing the predictions to measurements different faults can be detected and isolated. This can be done using, for example, a residual. An example of a residual $r(t)$ is the difference between a measured signal $y(t)$ and a prediction $\hat{y}(t)$ computed from the nominal model when fed with $u(t)$, see Figure 1.4. If the model describes the nominal fault-free system behavior, the predictions will deviate from the observations when a fault occurs. 


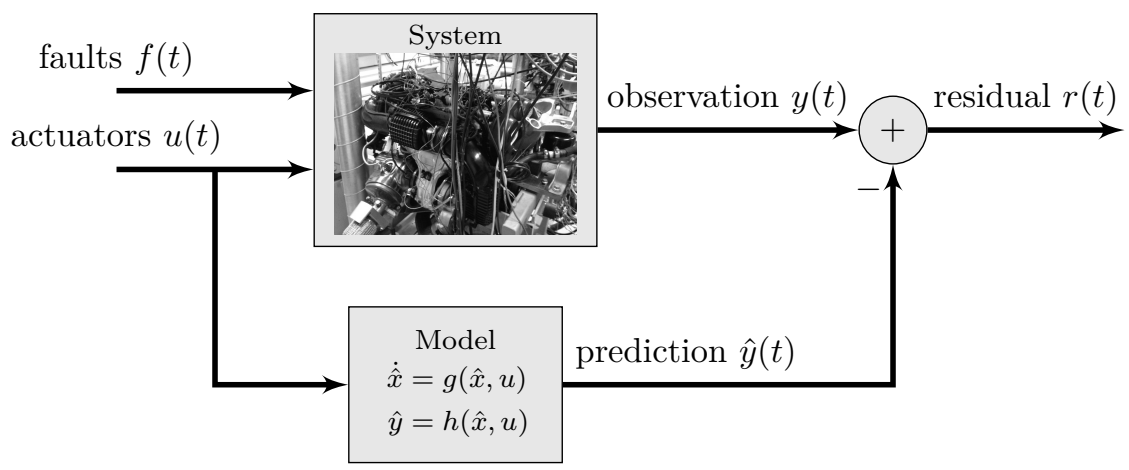

Figure 1.4: An example of a residual comparing measurements from the system $y(t)$ with model predictions $\hat{y}(t)$.

The term Fault Detection and Isolation, FDI, often relates to model-based diagnosis methods founded in control theory and focuses on the application of residual generators for fault detection, see for example (Gertler, 1991), (Isermann, 2005), (Blanke et al., 2006), and (Patton et al., 2010). Within the field of artificial intelligence, model-based diagnosis, sometimes denoted DX, focuses more on fault isolation and the use of logics to identify faulty behavior, see for example (Reiter, 1987), (de Kleer and Williams, 1987), (Feldman and van Gemund, 2006), and (de Kleer, 2011). A number of papers compare the different approaches from FDI and DX to bridge and integrate methods from the two fields (Cordier et al., 2004; Travé-Massuyès, 2014). In this thesis, diagnosis systems are considered where fault detection is mainly performed using methods from the FDI community and fault isolation is performed using methods from the DX community, see for example (Cordier et al., 2004).

\section{Fault detection}

There are many different methods in model-based diagnosis to design residual generators and overviews of different methods can be found in, for example, (Venkatasubramanian et al., 2003a) and (Ding, 2008). Common design methods are, for example, analytical redundancy relations (Staroswiecki and ComtetVarga, 2001; Cordier et al., 2004), possible conflicts (Pulido and González, 2004), but also different types of observers such as Kalman filters (Chen et al., 2011) and Extended Kalman Filters (Mosterman and Biswas, 1999; Huber et al., 2014).

The model predictions in the residuals are usually not perfect because of model uncertainties and measurement noise. Therefore, in order to determine if a residual has changed, different types of decision functions are used. An example of a residual output $r$ is shown in Figure 1.5 where a fault occurs at time 500. A threshold $J$ is used such that when the residual exceeds the threshold $J$ it triggers an alarm. The residual exceeds the threshold around time 600, indicating that a fault is detected. Other popular decision functions are based on hypothesis tests, for example, Cumulative Sum (CUSUM) tests (Page, 1954), which is an on-line recursively computed test, or generalized likelihood-ratio 


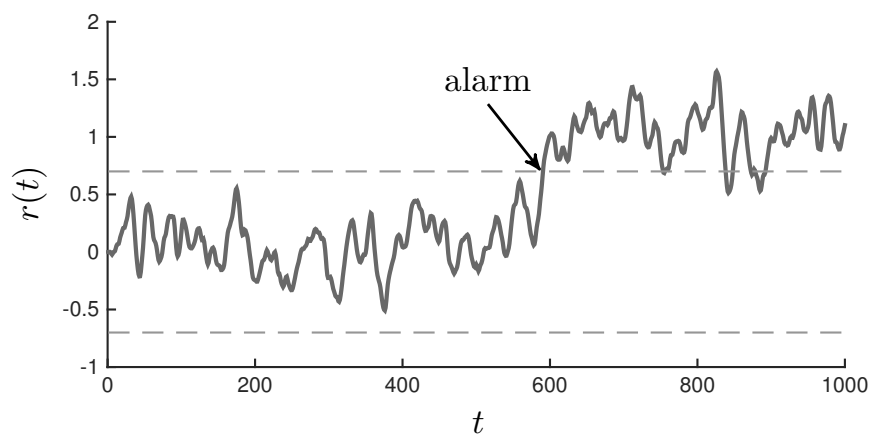

Figure 1.5: An example of a residual $r$ where a fault occurs at time $t=500$ and the residual triggers when it exceeds the threshold $J$ (dashed lines) around time $t=600$.

tests (Basseville and Nikiforov, 1993). A decision function is tuned to balance detection performance with risk of mis-classification, categorized as either false alarms or missed detections (Casella and Berger, 2001). By using information from different triggered residuals the fault can be isolated using some type of fault isolation strategy.

\section{Fault isolation}

In systems where more than one fault can occur, it is often not only sufficient to detect a fault but it is important to also isolate which fault that has occurred. If different residuals are designed such that each residual is sensitive to a different set of faults, fault isolation can be performed by comparing which residuals have triggered to the faults that each residual is sensitive to, called structured residuals (Gertler, 1998). The information of which faults each residual is sensitive to is often represented using a fault signature matrix, or decision structure. An example of a fault signature matrix is shown in Table 1.1 where an $\mathrm{X}$ in position $(i, j)$ represents that residual $r_{i}$ is sensitive to fault $f_{j}$. Fault isolation based on the fault signature matrix can then be performed using, for example, binary column-matching (Gertler, 1998) or fault isolation logic (de Kleer and Williams, 1987). Other related approaches are proposed, for example, in (Mosterman and Biswas, 1999) where fault detection and isolation are performed by also considering qualitative analysis of residual output transients.

As an example to describe the principles of the fault isolation logic in (de Kleer and Williams, 1987), consider a diagnosis system with three residuals $r_{1}, r_{2}$, and $r_{3}$ and the fault signature matrix shown in Table 1.1. Assume that residuals $r_{1}$ and $r_{2}$ have triggered. Comparing the residuals that have triggered with the decision structure shows that since both residuals are sensitive to fault $f_{1}$, it is a diagnosis since all alarms can be explained by the single fault. The other single faults $f_{2}$ and $f_{3}$ are not candidates since they cannot explain that both $r_{1}$ and $r_{2}$ have triggered. However, both $f_{2}$ and $f_{3}$ together can explain both triggered residuals. Thus, the two faults together $\left\{f_{2}, f_{3}\right\}$ is also a diagnosis candidate. 
Table 1.1: An example of a fault signature matrix where an $\mathrm{X}$ at position $(i, j)$ represents that residual $r_{i}$ is sensitive to a fault $f_{j}$.

\begin{tabular}{llll}
\hline & $f_{1}$ & $f_{2}$ & $f_{3}$ \\
\hline$r_{1}$ & $\mathrm{X}$ & & $\mathrm{X}$ \\
$r_{2}$ & $\mathrm{X}$ & $\mathrm{X}$ & \\
$r_{3}$ & & $\mathrm{X}$ & $\mathrm{X}$ \\
\hline
\end{tabular}

\subsection{Motivation for quantitative fault diagnosability analysis}

Analyzing fault diagnosability performance based on the model of the system is an important part of model-based design of diagnosis systems. It gives an understanding to which faults that can be detected and isolated, and which parts of the model that are best suited for designing residuals. Fault detectability and isolability can be evaluated, both for a given model and for a given diagnosis system. Evaluating fault detectability and isolability performance for a given diagnosis system are described in, e.g., (Chen and Patton, 1999).

There are different methods proposed to analyze fault detectability and isolability for different types of models. Fault detectability and isolability analysis of linear systems can be found in, for example, (Nyberg, 2002; Chen and Patton, 1999). For more general models, such as nonlinear models, fault detectability and isolability analysis is performed by analyzing a structural representation of the model equations which enables the analysis of a wider range of systems (Krysander, 2006; Travé-Massuyès et al., 2006; Ding, 2008). Fault detectability and isolability are deterministic properties meaning that previously proposed analysis methods often are too optimistic since the results only state whether a fault can be detected, and isolated, or not in theory. Since model uncertainties and measurement noise are not taken into consideration in the analysis, there is no difference if a good or bad sensor is used or if the faults to be detected are too small to be distinguished from the uncertainties.

For large or complex systems, where there are many available measurements or feedback and connections between different parts of the system, designing a diagnosis system is difficult and time-consuming to be done by hand. Different search algorithms have been proposed to, for example, find residual candidates with different deterministic fault detectability and isolability properties based on the model (Staroswiecki and Comtet-Varga, 2001; Krysander et al., 2008; Pulido and González, 2004), or find minimal sets of residuals that together can detect and isolate all possible faults (Rosich, 2012; Svärd, 2012). Another application is the sensor selection problem, where a cheapest set of sensors to be mounted in the system is sought that makes the considered faults detectable and isolable (Rosich, 2012; Raghuraj et al., 1999; Commault et al., 2008; Travé-Massuyès et al., 2006; Krysander and Frisk, 2008).

Since mainly fault detectability and isolability are used to define required diagnosability performance when formulating the optimization problem, it is likely the case that there are many optimal candidate solutions to these problems 
which are considered equally good. However, even if a set of residuals, or a set of sensors, fulfills required fault detectability and isolability in theory, the performance when implemented in the real system could be far worse than expected. By taking model uncertainties and measurement noise into consideration when formulating, for example, the residual or sensor selection problems, it is better assured that the final performance of the diagnosis system fulfills the requirements.

It is useful if fault detectability and isolability performance can be measured quantitatively based on the model of the system. Then, it is possible to relate achievable performance to specified requirements. If the requirements cannot be fulfilled given the model then more work can be focused on for example model improvements or adding sensors that would increase achievable fault diagnosability performance. If quantitative analysis also can be performed for a given residual generator and the whole diagnosis system, better decisions can be made during the design of the diagnosis system. As an example, three common measures of diagnosis test performance are probabilities of detection, missed detection, and false alarms. To evaluate these probabilities requires that a residual generator and a decision function is selected, meaning that the performance of both the residual generator and the decision function are evaluated together. If the residual generator can be evaluated without selecting a decision function, a residual generator with good detection performance can be designed first. Then, a suitable decision function can be tuned based on the optimized residual generator which should simplify the design problem since it can be divided in two steps. Another example is to use the model analysis to evaluate if the achieved performance of residual generators can be improved. For example, if predicted performance given the model indicates that achieved performance could be significantly improved, more work can be used to find better residual generators. A simple example of how the design process could proceed is shown in Figure 1.6 where fault diagnosability analysis is evaluated in each step of the design to validate against performance requirements. Thus, quantitative analysis can be used as feedback to an engineer during the development process to see how different design choices will improve the performance.

\section{$1.3 \quad$ Research topic}

This thesis considers the problem of how to quantify diagnosability performance in uncertain systems. One research goal is to investigate if fault diagnosability performance can be evaluated for a given model of the system when model uncertainties and measurement noise are taken into consideration. Different fault realisations, e.g. different magnitudes and behavior varying over time, and time allowed to detect the fault will also affect how difficult it will be to detect and isolate the fault. A quantitative performance measure should take these different factors into consideration. To get a useful interpretation of a quantitative diagnosability performance metric it is important to understand the relation to the diagnosability performance of a diagnosis system or specific residuals. This is necessary, for example, when relating the model analysis 


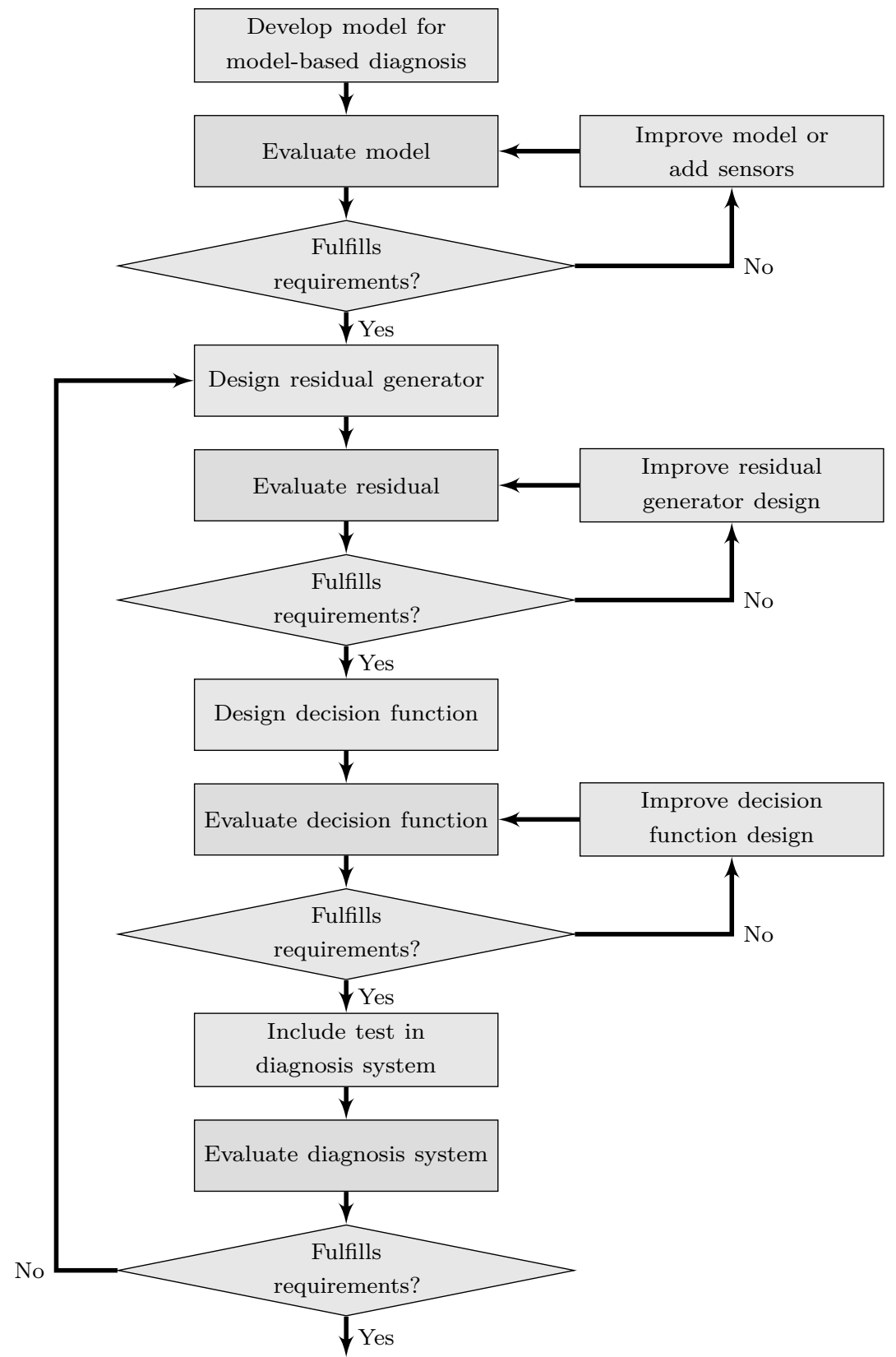

Done!

Figure 1.6: An example of how to proceed during the development of a diagnosis system using fault diagnosability analysis as feedback during the design process. By using quantitative diagnosability analysis, the evaluation in each step can be related to performance requirements of the final diagnosis system. This information can be used to speed up the design process by avoiding bad diagnosis system designs early in the design process. 
results to performance requirements. Then, performance requirements given the diagnosis system can be taken into consideration when formulating diagnosis system design problems, such as, sensor selection. Another goal is then to investigate how such a measure can be used during the design of different diagnosis functions as feedback to an engineer or to formulate optimization problems, such as the sensor selection problem, where model uncertainties and measurement noise are taken into consideration.

\subsection{Contributions}

The main contributions of Paper 1-6 are summarized below. Note that the author of this thesis changed his last name from Eriksson to Jung in September 2014.

\section{Paper 1}

Daniel Eriksson, Erik Frisk, and Mattias Krysander. A method for quantitative fault diagnosability analysis of stochastic linear descriptor models. Automatica, 49(6):1591-1600, 2013.

Paper 1 is an extended version of (Eriksson et al., 2011a) and (Eriksson et al., 2011b). The main contribution is the definition of distinguishability, based on the Kullback-Leibler divergence, which is used for quantitative fault detectability and isolability analysis of stochastic models and diagnosis systems. The second main contribution is the connection between distinguishability and linear residual generators for linear descriptor models with Gaussian noise. The author of this thesis contributed with the majority of this work including theory, implementation, and the written presentation.

\section{Paper 2}

Jan Åslund, Erik Frisk, and Daniel Jung. Asymptotic behavior of fault diagnosis performance. Submitted to a journal.

The main contribution of Paper 2 is an analytical expression of the asymptotic behavior of distinguishability when the time window increases, i.e., how performance changes with the amount of information used in diagnosis system. The analysis is done for faults with constant magnitude, as a function increasing time allowed to detect or isolate the fault. It is shown how the slope of the asymptote can be used as a quantitative diagnosability measure when the time allowed to detect a fault is not known. The paper also derives a higher order approximation of distinguishability as a function of time interval. The author of this thesis is the originator of the theoretical problem and has also contributed to the written presentation. 


\section{Paper 3}

Daniel Jung, Erik Frisk, and Mattias Krysander. Quantitative isolability analysis of different fault modes. 9th IFAC Safeprocess conference. Paris, France, 2015. (Accepted for publication)

The main contribution of Paper 3 is a quantitative measure of isolability performance, called expected distinguishability, when taking different fault realisations of a specific fault into consideration. Expected distinguishability is based on the distinguishability measure in Paper 1 and weights distinguishability with the probability of each fault realisation. The author of this thesis contributed with the majority of this work including implementations and the written presentation.

\section{Paper 4}

Daniel Jung, Yi Dong, Erik Frisk, Mattias Krysander, and Gautam Biswas. Sensor selection for fault diagnosis in uncertain systems. Submitted to a journal.

Paper 4 is an extended version of (Eriksson et al., 2012b) and the main contribution is the use of distinguishability for optimal sensor selection in time-discrete linear descriptor systems with Gaussian noise. The sensor selection problem is formulated as an optimization problem, where required fault detectability and isolability performance are taken into consideration by using minimal required distinguishability as constraints. Different properties of the search problem are investigated, where the complexity of the search problem motivates the need of a heuristic search strategy. A heuristic search algorithm, called greedy stochastic search, is proposed to find a solution close to global optimum in linear time and the performance is evaluated using Monte Carlo studies. The author of this thesis contributed with the majority of this work including design, implementations, and the written presentation.

\section{Paper 5}

Daniel Jung, Lars Eriksson, Erik Frisk, and Mattias Krysander. Development of misfire detection algorithm using quantitative FDI performance analysis. Control Engineering Practice, 34:49-60, 2015.

Paper 5 presents an engine misfire detection algorithm based on torque estimation using the flywheel angular velocity signal. The contribution is a misfire detection algorithm based on the estimated torque at the flywheel. A second contribution is the use of the Kullback-Leibler divergence for analysis and optimization of misfire detection performance. Evaluations using measurements from vehicles on the road show promising results with few mis-classifications, even in known difficult cases such as cold starts. The author of this thesis contributed with the majority of this work including design, implementations, and the written presentation. 


\section{Paper 6}

Daniel Jung, Erik Frisk, and Mattias Krysander. A flywheel error compensation algorithm for engine misfire detection. Submitted to a journal.

Paper 6 continues the development of the engine misfire detection algorithm in Paper 5 and the main contribution is a computationally cheap on-line algorithm, using the Constant Gain Extended Kalman Filter, to estimate and compensate for manufacturing errors of the flywheel. The estimated errors are compensated for in the misfire detection algorithm in Paper 5 and evaluations using measurements from vehicles on the road show that the modified misfire detection algorithm is robust against vehicle-to-vehicle variations. The author of this thesis contributed with the majority of this work including design, implementations, and the written presentation.

\subsection{Concluding remarks and future work}

The proposed distinguishability measure is able to quantify both fault detectability and isolability performance, both for a given model and for a given residual. A useful interpretation of the distinguishability measure is given by the relation to residual performance. This can be used when formulating performance requirements given the model that can be related to diagnosis system performance requirements.

The distinguishability measure can be used to formulate design optimization problems for different steps in the design process where the quantitative requirements are taken into consideration before a diagnosis system has been developed. It is shown both when formulating the sensor placement problem and when analyzing the misfire detection, before a detection algorithm had been developed, that distinguishability can give a lot of useful information about achievable performance already early in the design process. An interesting future work to further investigate from an industrial point of view is how performance requirements defined for a diagnosis system can be guaranteed early in a design process, for example, how to translate these requirements into required distinguishability levels when formulating a sensor selection problem. Another future work is to develop an algorithm that automatically designs a diagnosis system given a model of the system to be monitored, including information about uncertainties and faults, that (if possible) fulfills specified performance requirements.

The analysis using distinguishability in this thesis has mainly focused on timediscrete linear descriptor models with uncertainties modeled as Gaussian noise and additive fault signals. Nonlinear models can be analyzed by linearization around different operating points and computation of distinguishability for each operating point. However, it is still not investigated in the model analysis how to deal with the effects of, for example, parameter faults, parameter uncertainties, and transients when the system moves between different operating points. A future work is to investigate how to extend the quantitative fault diagnosability analysis framework to nonlinear systems such that these factors are taken into consideration. There is also a problem of how to extract and visualize useful 
information from these analyses, for example, if diagnosis performance varies for different operating conditions that are not known to a user.

\subsection{Publications}

The following papers have been published.

\section{Journal papers}

- Daniel Jung, Lars Eriksson, Erik Frisk, and Mattias Krysander. Development of misfire detection algorithm using quantitative FDI performance analysis. Control Engineering Practice, 34:49-60, 2015. (Paper 5)

- Daniel Eriksson, Erik Frisk, and Mattias Krysander. A method for quantitative fault diagnosability analysis of stochastic linear descriptor models. Automatica, 49(6):1591-1600, 2013. (Paper 1)

\section{Submitted}

- Jan Åslund, Erik Frisk, and Daniel Jung. Asymptotic behavior of fault diagnosis performance. (Paper 2)

- Daniel Jung, Yi Dong, Erik Frisk, Mattias Krysander, and Gautam Biswas. Sensor selection for fault diagnosis in uncertain systems. (Paper 4)

- Daniel Jung, Erik Frisk, and Mattias Krysander. A flywheel error compensation algorithm for engine misfire detection. (Paper 6)

\section{Conference papers}

- Hamed Khorasgani, Daniel Eriksson, Gautam Biswas, Erik Frisk, and Mattias Krysander. Robust residual selection for fault detection. 53rd IEEE Conference on Decision and Control. Los Angeles, CA, USA, 2014.

- Hamed Khorasgani, Daniel Eriksson, Gautam Biswas, Erik Frisk, and Mattias Krysander. Off-line robust residual selection using sensitivity analysis. 25th International Workshop on Principles of Diagnosis (DX-14). Graz, Austria, 2014.

- Daniel Eriksson, and Christofer Sundström. Sequential residual generator selection for fault detection. 13th European Control Conference (ECC2014). Strasbourg, France, 2014.

- Daniel Eriksson, Lars Eriksson, Erik Frisk, and Mattias Krysander. Flywheel angular velocity model for misfire and driveline disturbance simulation. 7th IFAC Symposium on Advances in Automotive Control. Tokyo, Japan, 2013. 
- Daniel Eriksson, Mattias Krysander, and Erik Frisk. Using quantitative diagnosability analysis for optimal sensor placement. 8th IFAC Safeprocess. Mexico City, Mexico, 2012.

- Daniel Eriksson, Erik Frisk, and Mattias Krysander. A sequential test selection algorithm for fault isolation. 10th European Workshop on Advanced Control and Diagnosis. Copenhagen, Denmark, 2012.

- Daniel Eriksson, Mattias Krysander, and Erik Frisk. Quantitative Fault Diagnosability Performance of Linear Dynamic Descriptor Models. 22nd International Workshop on Principles of Diagnosis (DX-11). Murnau, Germany, 2011.

- Daniel Eriksson, Mattias Krysander, and Erik Frisk. Quantitative Stochastic Fault Diagnosability Analysis. 50th IEEE Conference on Decision and Control. Orlando, Florida, USA, 2011.

- Erik Almqvist, Daniel Eriksson, Andreas Lundberg, Emil Nilsson, Niklas Wahlström, Erik Frisk, and Mattias Krysander. Solving the ADAPT Benchmark Problem - A Student Project Study. 21st International Workshop on Principles of Diagnosis (DX-10). Portland, Oregon, USA, 2010.

\section{Submitted}

- Daniel Jung, Erik Frisk, and Mattias Krysander. Quantitative isolability analysis of different fault modes. 9th IFAC Safeprocess conference. Paris, France, 2015. (Accepted for publication) (Paper 3)

- Daniel Jung, Hamed Khorasgani, Erik Frisk, Mattias Krysander, and Gautam Biswas. Analysis of fault isolation assumptions when comparing model-based design approaches of diagnosis systems. 9th IFAC Safeprocess conference. Paris, France, 2015. (Accepted for publication)

- Hamed Khorasgani, Daniel Jung, and Gautam Biswas. Structural approach for distributed fault detection and isolation. 9th IFAC Safeprocess conference. Paris, France, 2015. (Accepted for publication)

\section{Technical reports}

- Daniel Eriksson, Lars Eriksson, Erik Frisk, and Mattias Krysander. Analysis and optimization with the Kullback-Leibler divergence for misfire detection using estimated torque. Technical Report LiTH-ISY-R-305\%. Department of Electrical Engineering, Linköpings Universitet, SE-581 83 Linköping, Sweden, 2013. 


\section{Performance analysis in model based diagnosis}

Which models and sensors that are used for model-based diagnosis, how they are used, and what type of faults and fault magnitudes to detect, will have a significant impact on how difficult it is to detect and isolate faults. Model development is always a balance between model accuracy and development time. Measurement noise and model uncertainties will have a negative impact on the performance of diagnosis systems. Large uncertainties complicate detection of smaller faults which in that case will require more samples and longer time for detection to compensate for the uncertainties.

In this chapter, different quantitative measures of fault diagnosability performance are discussed. First, different proposed measures to quantify fault detection and isolation performance during different stages of the design process are discussed in Section 2.1. Also in Section 2.1, a slightly different and more informal derivation of the quantitive fault diagnosability measure, called distinguishability, proposed in Paper 1 is presented. Finally, the benefits of using a quantitative fault diagnosability measure in different diagnosis system design aspects are discussed in Section 2.2.

\subsection{Diagnosability analysis of uncertain systems}

There exists a number of methods for quantitative evaluation of fault diagnosability performance. Performance is evaluated either given a model, a specific test, or the whole diagnosis system. A (diagnosis) test refers to when a residual and a decision function are evaluated together.

Measures used in classical detection theory for analyzing detectability performance of specific tests are probabilities of detection, false alarm, and missed detection (Basseville and Nikiforov, 1993; Kay, 1998). These measures are often 

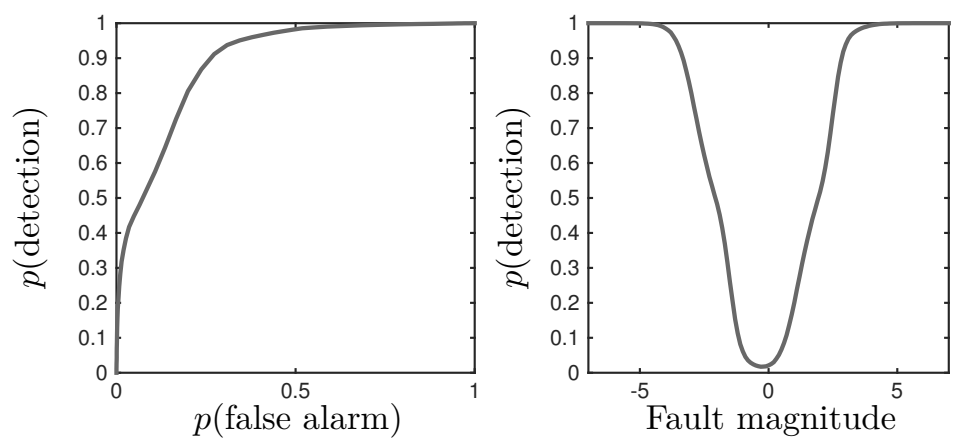

Figure 2.1: An example of a ROC-curve in the left plot and a power function in the right plot.

used to define required detection performance of individual tests or diagnosis systems and are therefore evaluated late in the development process. Computing the probabilities requires that the distributions of the residual for the fault-free case and faulty case are known, or that realistic approximations are available using data. Other probabilistic methods for analyzing test performance are, for example, Receiver Operating Characteristics, or ROC curves, (Kay, 1998) to evaluate the relation between probability of detection and false alarm rate, and power functions (Casella and Berger, 2001) to evaluate probability of detection given faults of different magnitudes, see Figure 2.1. These methods consider fault detection performance and not fault isolation performance which is also important when evaluating fault diagnosability. Also, when designing residual generators, it would be useful if the residual generator performance could be evaluated before a decision function is selected to compare different residual generator candidates. Since these measures evaluate the performance for a given test it is necessary that a decision function is selected. The distinguishability measure proposed in Paper 1 can be used to quantify the separation between fault-free and faulty data before a decision function is selected.

Methods for analyzing fault detectability and isolability performance for a given diagnosis system, using probabilistic measures, are found in several works, e.g., (Wheeler, 2011; Krysander and Nyberg, 2008; Chen and Patton, 1996; Willsky and Jones, 1976), and (Emami-Naeini et al., 1988). The methods in these papers take model uncertainties and measurement noise into consideration. There are quantitative performance metrics related to how long time it takes to detect or isolate a fault, for example Average Run Length (Basseville and Nikiforov, 1993), Mean Time To Detect (MTTD) (Chen and Adams, 1976), and Mean Time To Isolate (MTTI) (Daigle et al., 2013). However, since the methods analyze fault detectability or isolability performance for a given diagnosis system, or a specific test, they can only be applied after a test or diagnosis system has been designed.

In robust fault diagnosis, residual performance is optimized by maximizing the effect of faults and minimizing the influence of disturbances (Hamelin and 
Sauter, 2000; Chen et al., 2003). In (Khorasgani et al., 2014), fault detection and isolation performance of a residual is quantified using sensitivity analysis to compare fault and uncertainty propagation to residual outputs where faults and uncertainties are assumed bounded. In (Ingimundarson et al., 2009; Jauberthie et al., 2013), set-membership methods are also used to represent uncertainties using bounded intervals. With respect to the works using set-membership approaches, a stochastic framework is used in this thesis where uncertainties are represented by probability distributions.

Fault detectability and isolability can be quantified for a given model by using performance metrics that quantifies the separation between measurements from different faults (Cui et al., 2014), for example the Kullback-Leibler divergence (Basseville, 2001). Comments regarding the paper (Basseville, 2001) are presented in (Kinnaert et al., 2001) where Nyberg suggests that the KullbackLeibler divergence can be a suitable candidate measure to quantify isolability performance for a given model when using stochastic representations of each fault mode. This idea has several similarities with the distinguishability measure proposed in Paper 1. Another interesting measure to quantify isolability performance for a given model, also proposed in (Basseville, 2001), is the Fisher information which can be seen as a measure of fault information content in measurements.

Many fault diagnosability performance metrics are defined for a given diagnosis system or a specific test. However, quantitative performance analysis of models is an interesting problem since it allows for performance evaluation before a diagnosis system design has been decided. The Kullback-Leibler divergence quantifies the separation between different probability density functions. It can also be related to optimal residual performance when interpreting the analysis results from a model analysis. Therefore, it is an interesting candidate to quantify diagnosability performance for a given model but also for a given residual generator since it does not require a decision function to be evaluated. In Paper 5, engine misfire detection performance is quantified using KullbackLeibler divergence by measuring the separation between measurements from the fault-free case and faulty case at different operating conditions.

\subsubsection{Distinguishability}

An informal derivation of the quantitative diagnosability measure proposed in Paper 1 is presented starting from residual performance using the Neyman-Pearson lemma (Casella and Berger, 2001). The residual is a function of observations from the system and is affected by model uncertainties and measurement noise. If the uncertainties are represented by random variables, the residual output can be described by different probability density functions (pdf) depending on which faults are present. Assume that the pdf of a residual $r(t)$ is $p_{\mathrm{NF}}(r)$ in the nominal (No Fault) case and $p_{f_{i}}(r)$ when there is a fault $f_{i}$ in the system. Then, the Neyman-Pearson lemma states that the most powerful test of size $\alpha$, i.e., the false alarm rate, for a threshold $J$ to reject the null hypothesis $H_{0}$ that the system is fault-free in favor of the alternative hypothesis $H_{1}$ that $f_{i}$ is present is 
given by the likelihood ratio test

$$
\Lambda(r)=\frac{p_{f_{i}}(r)}{p_{\mathrm{NF}}(r)}>J \text { where } P\left(\Lambda(r)>J \mid H_{0}\right)=\alpha .
$$

How much the pdf $p_{f_{i}}(r)$ differs from the pdf $p_{N F}(r)$ in (2.1) can be interpreted as how easy it is to distinguish a fault $f_{i}$ from the system's nominal behavior, i.e., how much more likely is $r$ given $p_{f_{i}}$ compared to $p_{N F}$. The Neyman-Pearson lemma states that the (log-)likelihood ratio test is the most powerful test for any threshold $J$. Thus, a quantitive fault detection performance measure of $r$ for detecting a fault $f$ is the expected value of the log-likelihood ratio when a fault is present, i.e.

$$
\mathbb{E}_{p_{f_{i}}}\left[\log \left(\frac{p_{f_{i}}(r)}{p_{\mathrm{NF}}(r)}\right)\right]=\int_{-\infty}^{\infty} p_{f_{i}}(x) \log \frac{p_{f_{i}}(x)}{p_{\mathrm{NF}}(x)} d x
$$

where $\mathbb{E}_{p}[q(x)]$ is the expected value of the function $q(x)$ when the distribution of $x$ is given by $p(x)$. Expression (2.2) can be interpreted as the expected log-likelihood ratio when the fault $f_{i}$ is present in the system. A large value of (2.2) corresponds to when the log-likelihood is likely to be large when there is a fault $f_{i}$ and, thus, it should be easy to detect $f_{i}$ using the residual $r(t)$. Note that (2.2) does not depend on any threshold $J$ and can be seen as a quantitative performance measure of the residual $r(t)$ without taking $J$ into consideration. Expression (2.2) is known as the Kullback-Leibler divergence from $p_{f_{i}}$ to $p_{\mathrm{NF}}$ denoted $K\left(p_{f_{i}} \| p_{\mathrm{NF}}\right)$, see (Kullback and Leibler, 1951). The Kullback-Leibler divergence is non-negative and is zero if and only if $p_{f_{i}}=p_{\mathrm{NF}}$, i.e. when it is not possible to distinguish between the fault modes $f_{i}$ and NF since the expected $\log$-likelihood ratio test is zero. Note that if $r(t)$ is not sensitive to $f_{i}$, the pdf of $r(t)$ will not change from the nominal case when the fault $f_{i}$ is present in the system, i.e. $p_{f_{i}}=p_{\mathrm{NF}}$. The Kullback-Leibler divergence itself has also been used as a hypothesis test for fault detection in, for example, (Zeng et al., 2014; Svärd et al., 2014) and (Bittencourt et al., 2014). An interesting analysis of the Kullback-Leibler divergence using the Neyman-Pearson lemma is found in (Eguchi and Copas, 2006).

The Kullback-Leibler divergence (2.2) describes fault detectability performance for a given residual $r(t)$ but can also be used to describe fault isolability performance in the same way. To see how (2.2) can be used to quantify fault isolability performance using a residual $r(t)$, assume that $r(t)$ is sensitive to two faults, $f_{i}$ and $f_{j}$. The corresponding pdf's of $r(t)$ given each fault is $p_{f_{i}}$ and $p_{f_{j}}$ respectively, meaning that it is possible to isolate the faults from each other by determining which pdf $r(t)$ is drawn from. Then, to evaluate how difficult it would be to isolate $f_{i}$ from $f_{j}$ can be written as

$$
K\left(p_{f_{i}} \| p_{f_{j}}\right)=\mathbb{E}_{p_{f_{i}}}\left[\log \left(\frac{p_{f_{i}}(r)}{p_{f_{j}}(r)}\right)\right]
$$

where the pdf $p_{\mathrm{NF}}$ in $(2.2)$ is replaced by $p_{f_{j}}$.

Different faults can occur with different magnitudes and influence a system in different ways, meaning that isolating the fault $f_{i}$ from another fault $f_{j}$ may 


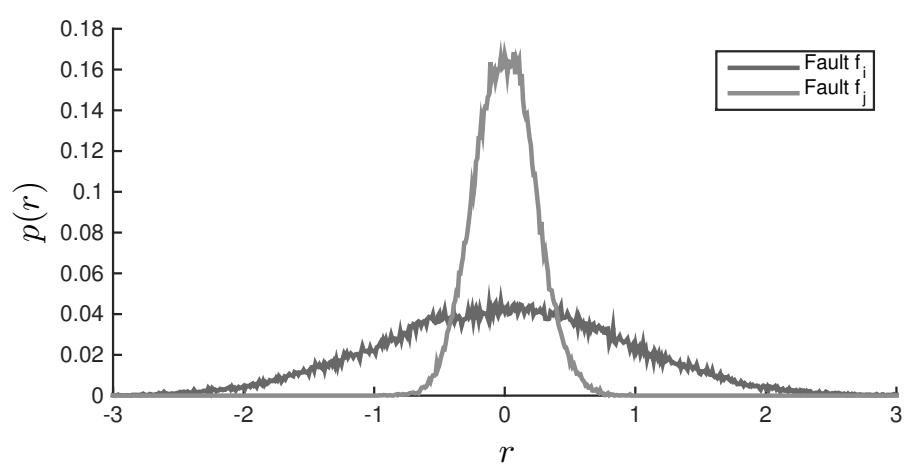

Figure 2.2: The pdf of a residual $r$ given two different faults $f_{i}$ and $f_{j}$. A residual output in the interval $[-1,1]$ can be explained by both faults while larger values is more likely to be measured given fault $f_{i}$ and not likely given $f_{j}$ since the pdf is almost zero. In this example it is easier to isolate $f_{i}$ from $f_{j}$ than the opposite.

not be as easy as isolating $f_{j}$ from $f_{i}$. Figure 2.2 show two pdf's representing the residual output given two different faults. It is easier to isolate $f_{i}$ from $f_{j}$ since there is a relatively high chance of measuring samples which are likely given $f_{i}$ but not $f_{j}(|r(t)|>1)$. However, samples that are likely given $f_{j}$ are also likely given $f_{i}$, meaning that even if $f_{j}$ is the fault present, the residual output could still be explained by the fault $f_{i}$. This type of asymmetry is captured by the Kullback-Leibler divergence since $K\left(p_{f_{i}} \| p_{f_{j}}\right) \neq K\left(p_{f_{j}} \| p_{f_{i}}\right)$ in general.

In practice, a fault can have many different realizations, such as different magnitudes and fault trajectories, meaning that the distribution of $r(t)$ can be described by different pdf's $p_{f_{i}}$ for a given fault mode $f_{i}$ depending on the fault realization. An example is shown in Figure 2.3 where different fault magnitudes result in different residual distributions. Each fault realization is represented by a pdf shown by the vertical histograms where $p_{\mathrm{NF}}$ is the fault-free pdf and $p_{f_{i}}^{k}$ represents the pdf of fault realization $k$ given fault mode $f_{i}$.

Let $\mathcal{Z}_{f_{j}}$ denote the set of all possible pdf's of $r$ given fault mode $f_{j}$, i.e., when a fault $f_{j}$ of any magnitude or trajectory has occurred. Then, a quantitative measure of how difficult it is to isolate a fault $f_{i}$, when the pdf of $r(t)$ is $p_{f_{i}}$, from another fault $f_{j}$ of any realization can be defined as the smallest Kullback-Leibler divergence from $p_{f_{i}}$ to any $p_{f_{j}} \in \mathcal{Z}_{f_{j}}$, denoted

$$
\mathcal{D}_{i, j}(\theta)=\min _{p_{f_{j}} \in \mathcal{Z}_{f_{j}}} \mathbb{E}_{p_{f_{i}}}\left[\log \left(\frac{p_{f_{i}}(r(\theta))}{p_{f_{j}}(r(\theta))}\right)\right]
$$

where $\theta$ is a vector representing the fault signal of fault mode $f_{i}$ resulting in pdf $p_{f_{i}}$. The notation $r(\theta)$ is here used to emphasize that the output of $r$ depends on the fault realization $\theta$. In Paper 1 , a quantitative fault diagnosability measure is proposed where (2.4) is computed based on the model instead of the residual $r$, and is called distinguishability. A graphical visualization of distinguishability is shown in Figure 2.4 where the fault modes $f_{i}$ and $f_{j}$ are represented by $\mathcal{Z}_{f_{i}}$ and 


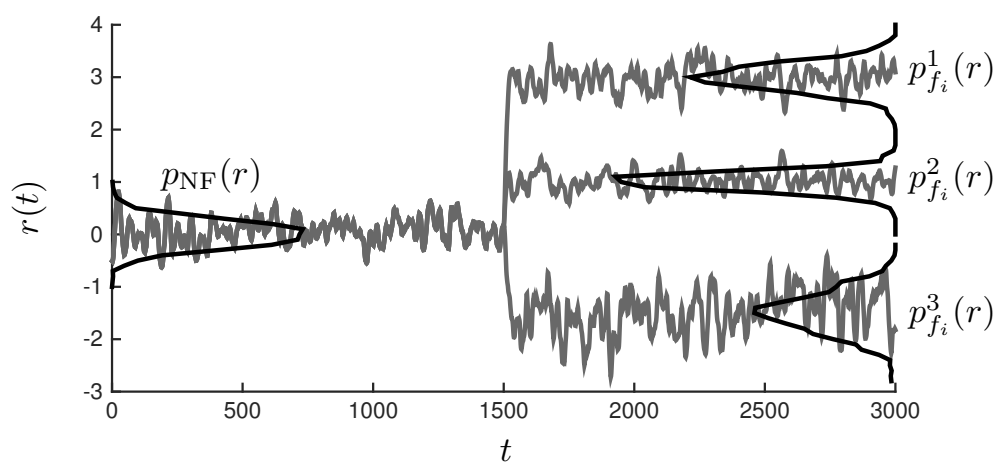

Figure 2.3: Example of different residual outputs caused by different fault realizations. Each fault realization is represented by a pdf describing the residual output.

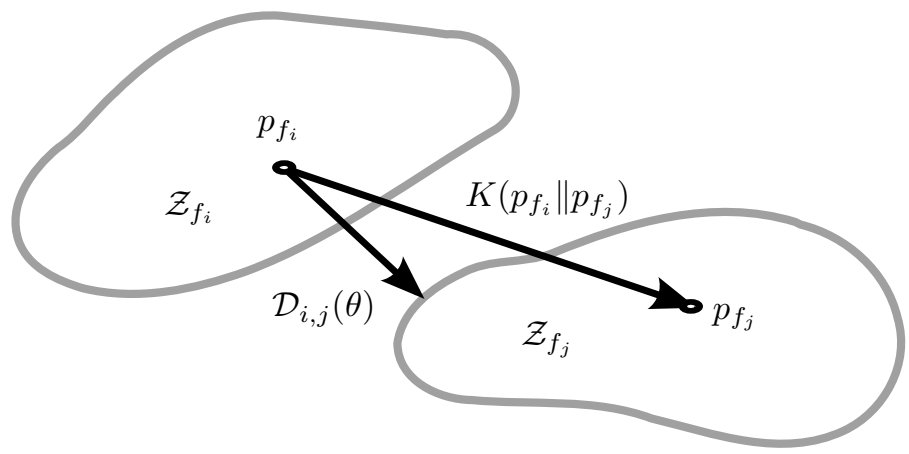

Figure 2.4: A graphical visualization of the sets $\mathcal{Z}_{f_{i}}$ and $\mathcal{Z}_{f_{j}}$ and the smallest difference between $p_{\theta_{a}}^{i} \in \mathcal{Z}_{f_{i}}$ and any pdf $p^{j} \in \mathcal{Z}_{f_{j}}$ is given by $\mathcal{D}_{i, j}(\theta)$.

$\mathcal{Z}_{f_{j}}$ and distinguishability is the smallest Kullback-Leibler divergence from $p_{f_{i}}$ to any element $p_{f_{j}} \in \mathcal{Z}_{f_{j}}$. The same measure of diagnosability performance has also been proposed in (Harrou et al., 2014). Note that if $\mathcal{Z}_{f_{j}}$ only contain one element $p_{f_{j}}$, (2.4) simplifies to (2.3). Further analysis of the distinguishability measure is presented in Paper 2 describing the asymptotic behavior when increasing the time allowed to detect or isolate the fault. Paper 3 presents a generalization of the distinguishability measure by taking the probabilities of different fault realization into consideration.

The distinguishability measure is useful since it can quantify fault detectability and isolability performance given a model of the system and the NeymanPearson lemma gives a practical interpretation of the measure related to optimal residual performance. Then when defining a diagnosis system design problem, required fault detectability and isolability performance can be specified using distinguishability where the requirements are set based on required residual performance. 


\subsection{Design aspects of diagnosis systems}

There are several decisions that have to be made regarding different parts of the diagnosis system design. Either if the diagnosis system is designed manually by an engineer or generated automatically by a design tool, well motivated decisions will hopefully result in a solution with satisfactory performance. However, if different factors such as model uncertainties and measurement noise are not taken into consideration early in the design process, later evaluations of the diagnosis system could show that performance requirements are not fulfilled and previous steps in the design must be repeated, thus, resulting in unnecessary long development time. Also, as argued in (Svärd, 2012), automated design methods can reduce mistakes due to the human factor. Using more accurate performance metrics will improve the result of the automated design methods since the actual required performance better can be taken into consideration.

A problem that can be considered early in the diagnosis system design process is the sensor selection problem since the possibility of designing different residual generators to detect and isolate different faults depends on which sensors are available in the system. The sensor selection problem is a combinatorial search problem and the goal is usually to find a cheapest set of available sensors such that required fault detectability and isolability can be achieved, see (Rosich, 2012; Raghuraj et al., 1999; Commault et al., 2008; Travé-Massuyès et al., 2006; Krysander and Frisk, 2008), and (Frisk et al., 2009). In previous works, deterministic fault detectability and isolability performance are considered when formulating the constraints of the solution. Since the uncertainties are not taken into consideration in the problem formulation, there can be many optimal solutions that in practice will give completely different results. In Paper 4, the distinguishability measure is applied when defining the sensor selection problem and the quantitative performance requirements are shown to have a significant impact on the solutions found. Distinguishability has also been applied when formulating the sensor selection problems in (Huber et al., 2014) and (Kinnaert and Hao, 2014). In (Huber et al., 2014), the purpose was to design an Extended Kalman Filter to estimate faults in an internal combustion engine and simulations show that the sensor solution with higher distinguishability also gave better fault estimation performance.

Once the available sensors and the model of the system are specified, one of the next design problems considers the design and selection of test quantities such that the diagnosis system fulfills a required fault detectability and isolability performance. For systems with high redundancy the number of residual candidates is larger and different search algorithms are proposed to automatically find residual candidates. One type of residual candidates are those designed using a minimum amount of sensors and model equations, referred to as for example Minimal Structurally Overdetermined (MSO) sets (Krysander et al., 2008) or Structural Analytical Redundancy Relations (SARRs) (Pulido and González, 2004). A comparison of different methods is presented in (Armengol Llobet et al., 2009). The test selection problem that follows, i.e. to select a suitable subset of residual generator candidates that can detect and isolate a set of faults is also a combinatorial problem and can be solved by for example greedy search (Svärd, 
2012) or binary integer linear programming (Rosich et al., 2012). To be able to isolate all faults as good as possible might require lots of residuals which can be computationally costly if all residuals are used at the same time. Thus, the test selection problem can also be considered on-line where a sequential test selection strategy updates which test quantities to be active during a scenario to reduce computational cost while maintaining isolability performance (Krysander et al., 2010). In (Eriksson et al., 2012a), distinguishability is used in the sequential test selection problem to always select the residuals with best performance in each step of the fault isolation process. 


\section{Engine misfire detection performance analysis}

In the previous chapter, different quantitative fault diagnosability measures and their applications are discussed. The distinguishability measure is proposed as a suitable candidate measure since it does not require that a decision function has been selected and is related to detection performance. It is interesting to evaluate how quantitative analysis can be used on a real system to evaluate performance before a diagnosis system has been developed, for example as a feedback during the diagnosis system design. In the automotive industry, the on-board diagnosis (OBDII) legislations require that many systems in a vehicle are monitored on-line to prevent faults that potentially lead to increased emissions, increased fuel consumption, or damage to important parts of the vehicle. An overview of automotive diagnosis research is found in (Mohammadpour et al., 2012).

One example of an automotive diagnosis application is engine misfire detection. Misfire refers to an incomplete combustion inside a cylinder and can be caused by many different factors, for example a fault in the ignition system or clogging in the fuel injection system, see (Heywood, 1988). Misfire detection is an important part of the OBDII legislations in order to reduce exhaust emissions and avoid damage to the catalytic converters. The legislations require that the on-board diagnosis system is able to both detect misfires and identify in which cylinder the misfire occurred (Heywood, 1988; Walter et al., 2007; Mohammadpour et al., 2012). Misfires can be intermittent from one or several cylinders, or persistent from a complete cylinder failure. The legislations also define strict requirements in terms of the amount of allowed missed misfire detections. However, to avoid unnecessary visits to the workshop and dissatisfied customers, it is also required 
that the number of false alarms is minimized. To fulfill both conditions is difficult and imposes tough requirements on the development and tuning of the misfire detection algorithm.

A summary of existing methods for misfire detection is presented in Section 3.1. Then, misfire detection using the crankshaft angular velocity measured at the flywheel is introduced in Section 3.2. Finally, quantitative performance analysis is applied to flywheel measurements in Section 3.3 to evaluate misfire detection performance at different operating points and for different cylinders using the Kullback-Leibler divergence.

\subsection{Approaches to engine misfire detection}

Engine misfire detection is one of the computationally significant parts in the on-board diagnosis system and there are several different algorithms proposed to detect misfires (Mohammadpour et al., 2012). Examples of approaches are to directly monitor the quality of the combustion using ion current sensors (Auzins et al., 1995; Fan et al., 2014; Lundström and Schagerberg, 2001), to measure engine vibration using an accelerometer mounted on the engine block (Chang et al., 2002; Sharma et al., 2014; Sugumaran et al., 2010), or to detect temperature variations in the exhaust manifold (Tamura et al., 2011). These methods usually require additional sensors that are not generally available in the vehicle. Therefore, an available signal that is commonly used to detect misfires is the crankshaft angular velocity measured at the flywheel (Williams, 1996; Osburn et al., 2006; Naik, 2004; Tinaut et al., 2007).

Several misfire detection methods use the flywheel angular velocity signal to estimate different system states describing the combustion quality using physically based models. One approach is torque estimation and has been studied in, e.g, (Connolly and Rizzoni, 1994; Kiencke, 1999; Walter et al., 2007). The purpose is to recreate the torque generated by the cylinders to detect torque drops due to misfire. Paper 5 proposes a computationally simple misfire detection algorithm using estimated torque. The detection algorithm is automatically calibrated using training data, is easy to tune, and achieves good detection performance with few mis-classifications. Other model-based approaches using the crankshaft angular velocity considers estimating the cylinder pressures (Molinar-Monterrubio and Castro-Linares, 2007) or the relative changes in kinetic energy during compression and expansion stroke (Tinaut et al., 2007).

\subsection{Misfire detection based on crankshaft angular velocity measurements}

The flywheel is mounted on the crankshaft before the transmission. A photo of a flywheel is shown in Figure 3.1, where a Hall effect sensor is mounted close to the flywheel and triggers when the punched holes, or teeth, pass the sensor. The flywheel angular velocity signal measures the elapsed time it takes between two holes on the flywheel to pass the Hall sensor. The punched holes give an 


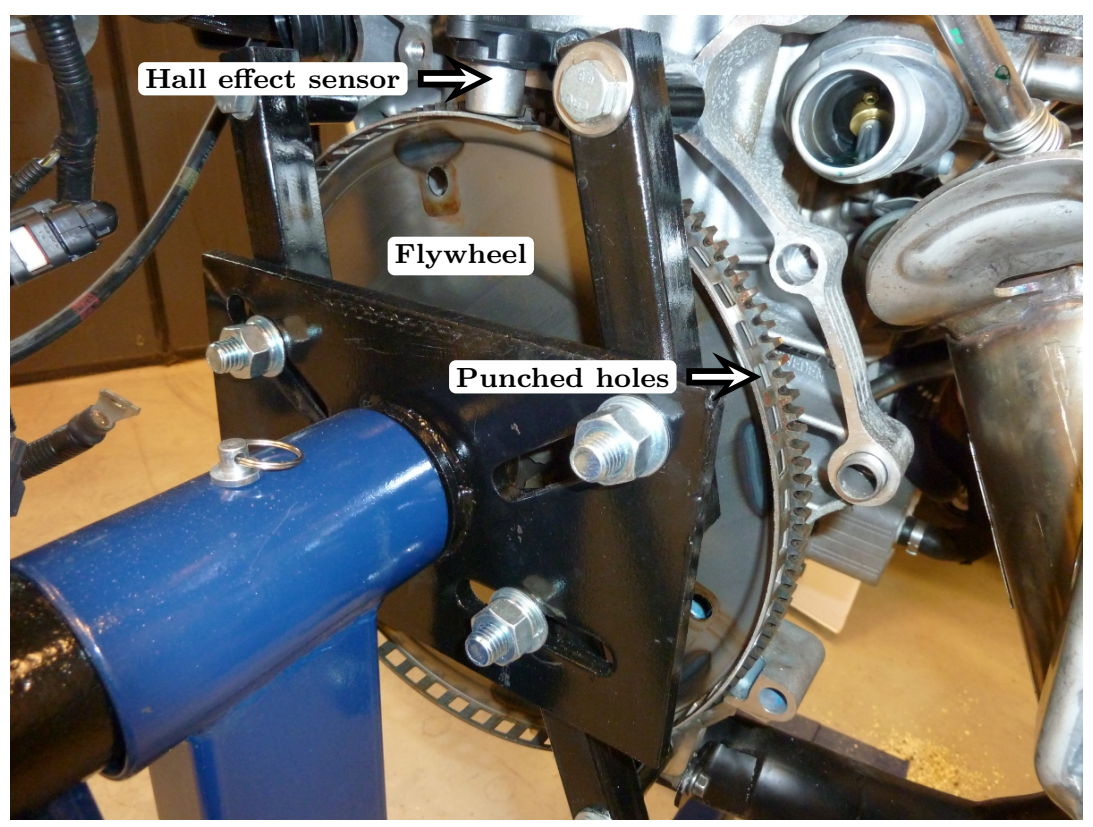

Figure 3.1: A picture of a flywheel and the Hall effect sensor.

angular resolution of $6^{\circ}$, however, two following holes are removed resulting in 58 punched holes, where the longer interval without holes is used to keep track of the flywheel angle. Sometimes, the flywheel signal is "down-sampled" by measuring the elapsed time for longer angular intervals (Naik, 2004; Osburn et al., 2006).

An example of the flywheel angular velocity signal from a vehicle with a six-cylinder engine and an angular resolution of $30^{\circ}$ is shown in Figure 3.2. Each firing cylinder is observable in the flywheel angular velocity signal as a short decrease in measured elapsed time, i.e. an increase in the crankshaft angular velocity, while a misfire causes a sudden increased measured elapsed time for the angular interval. However, even if a misfire is clearly visible in the figure, detecting misfires is a non-trivial problem which is complicated by, for example, large operating range of the engine, varying working conditions such as cold starts, and flywheel manufacturing errors, see (Naik, 2004) and (Kiencke, 1999). Flywheel manufacturing errors here cover both flywheel tooth angle errors (inaccuracies in the intervals between the punched holes) and eccentric mounting of the flywheel. This has the result that the measured time between two holes, or teeth, is measured over non-uniform angular intervals of the flywheel. This results in vehicle-to-vehicle variations in the measurements that should be compensated for to achieve robustness in the misfire detection algorithm. Both in (Weißenborn et al., 2011) and Paper 6, the estimated flywheel tooth angle errors were in an interval of around $\pm 0.06^{\circ}$. The results when using a flywheel error compensation algorithm proposed in Paper 6 show that even these small magnitudes can have a significant negative impact on misfire detection 


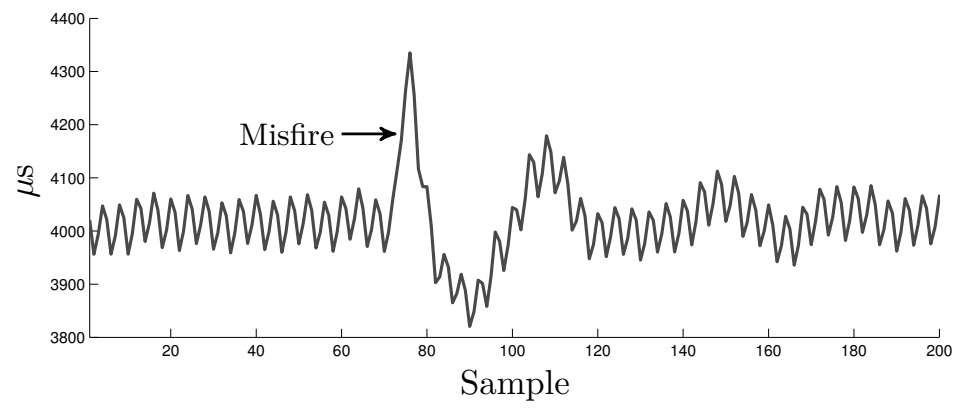

Figure 3.2: Flywheel angular velocity signal when a misfire occurs. Each firing cylinder is visible as short drop in the signal while a misfire result in a significant increase in elapsed time.

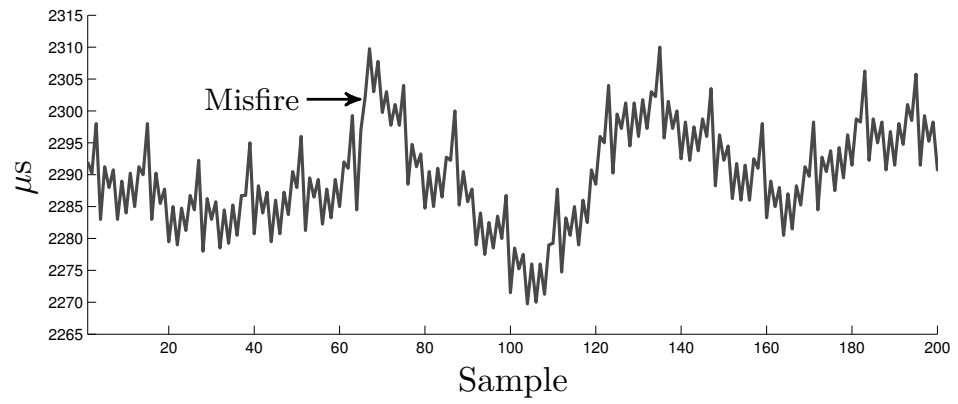

Figure 3.3: Flywheel angular velocity signal when a misfire occurs from a different vehicle and different operating point compared to Figure 3.2. It is more difficult to distinguish each firing cylinder in the signal and the effect of a misfire on the signal is smaller.

performance if not compensated for.

Figure 3.3 shows measurements from another vehicle at a different operating point, which has a different characteristic compared to Figure 3.2. The varying characteristics of the signal, but also the varying effect of a misfire, will have an impact on misfire detection performance that will depend on operating point.

\subsection{Quantitative analysis of misfire detection performance}

The mean value of the flywheel signal varies fast depending on speed and it is difficult to compare measurements from similar conditions. Therefore, the flywheel signal is used to compute estimated cylinder torque which varies less during similar operating conditions and is easier to use to evaluate misfire detection performance. During similar operating conditions, the behavior of 
fault-free combustions and misfires do not change much, meaning that fault-free data and misfire data can be described by one pdf respectively. To quantify the separation between fault-free data and misfire data, the distinguishability measure (2.4) simplifies to the Kullback-Leibler divergence. The KullbackLeibler divergence is computed using estimated torque around different operating points where the pdf's of fault-free data and misfire data are estimated from measurements associated to the combustions in each cylinder respectively. The angular resolution of the flywheel signal is $30^{\circ}$ which means that there are 24 samples in each cycle and thus 4 samples during each combustion for a six cylinder engine, see Figure 3.4. Figure 3.5 shows estimated torque related to cylinder one from two different operating points, where the last three of four samples during a combustion, both from fault-free data and misfire data, are plotted against each other. The gray dots are projections on the different 2D planes to better visualize the separation between the different data sets. The operating point is defined by speed $\omega[\mathrm{rpm}]$ and load, here represented by air mass induced per revolution $m_{\mathrm{a}}[\mathrm{g} / \mathrm{rev}]$. The estimated torque is scaled with respect to a reference torque. The separation between fault-free data and misfire data is larger in the lower plot compared to the upper indicating that it should be easier to detect misfires in that case with fewer mis-classifications. The Kullback-Leibler divergence is a way to quantify the separation and is computed for the two cases where a higher Kullback-Leibler divergence is visible as a larger separation between the fault-free data and misfire data. Thus, the KullbackLeibler divergence is used as a quantitive measure of how difficult it is to detect misfires in different operating points before a misfire detection algorithm has been developed.

Results when evaluating performance using measurements from three vehicles are shown in Figure 3.6 where each plot represents misfire detection performance from one cylinder. The analysis shows that the Kullback-Leibler divergence increases with increasing speed and load, indicating that it is easier to detect misfires with increasing speed and load. Also, when comparing data from the different cylinders, it is visible that cylinder six has a lower Kullback-Leibler divergence compared to the other cylinders meaning that it should be more difficult to detect misfires in cylinder six. This type of information indicates that more effort is necessary at low speed and load, but also for estimated torque from cylinder six, to achieve low mis-classification rate. The last result can be motivated by the fact that cylinder six is mounted furthest away from the flywheel and closest to a damping wheel which probably damps out the effects of misfires at the flywheel. The type of analysis using the results in Figure 3.6 can be made during the design process to evaluate, for example, at which operating conditions it is most difficult to classify misfires. In Paper 5, comparisons of the results before and after making modifications to the misfire detection algorithm, are used to motivate which design choices that will improve detection performance. 


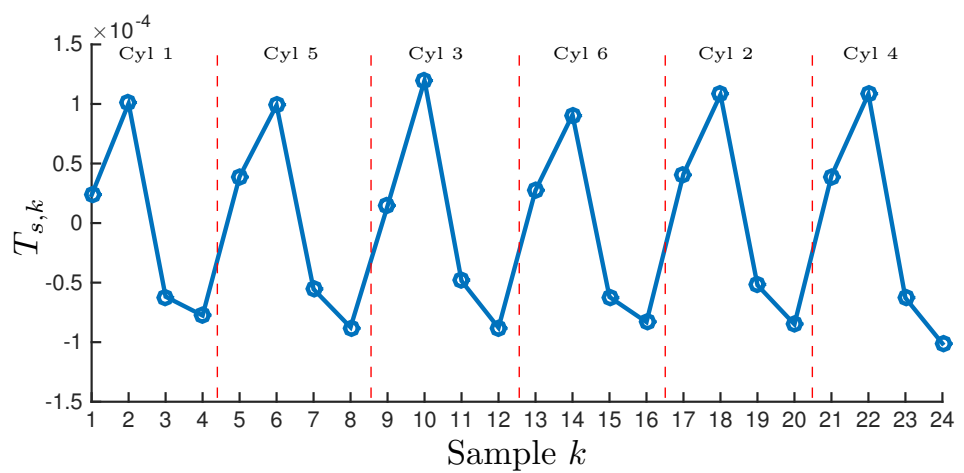

Figure 3.4: Example of samples of scaled estimated torque $T_{s, k}$ from one cycle where each four samples are related to a cylinder.
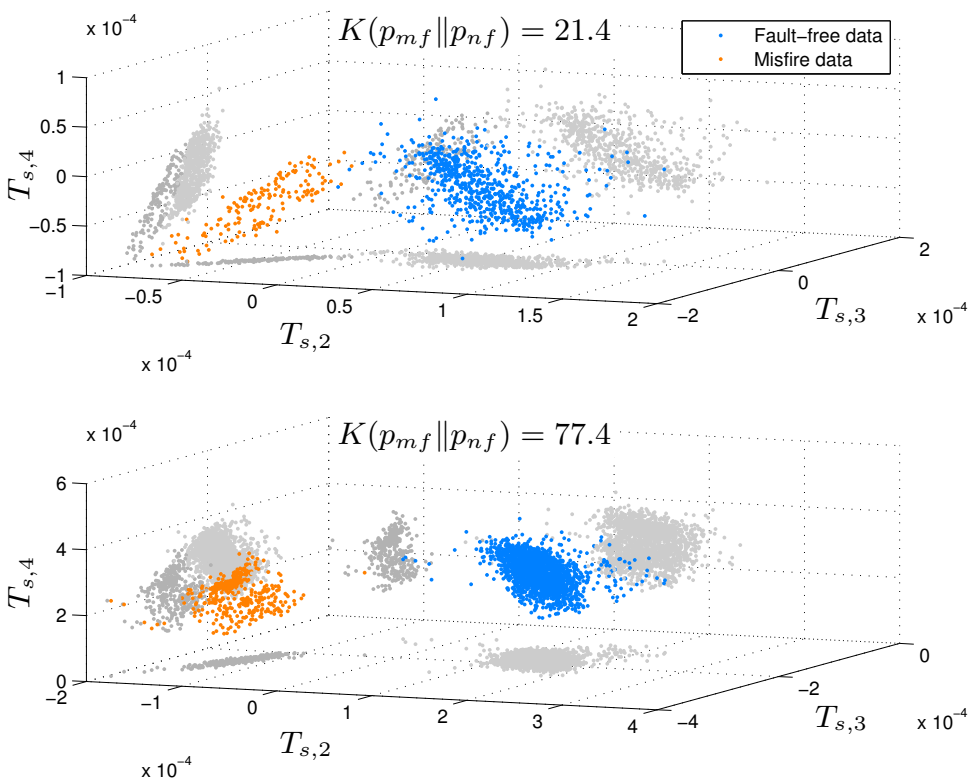

Figure 3.5: The estimated torque from the last three of four samples related to cylinder one are plotted against each other where the estimated torque is scaled with respect to a reference torque. The Kullback-Leibler divergence is computed using estimated torque data at $\omega=1000 \mathrm{rpm}$ and $m_{\mathrm{a}}=0.45 \mathrm{~g} / \mathrm{rev}$ in upper plot and $\omega=2800 \mathrm{rpm}$ and $m_{\mathrm{a}}=0.9 \mathrm{~g} / \mathrm{rev}$ in lower plot where a higher value corresponds to a larger separation between fault-free data and misfire data. 
Cylinder 1

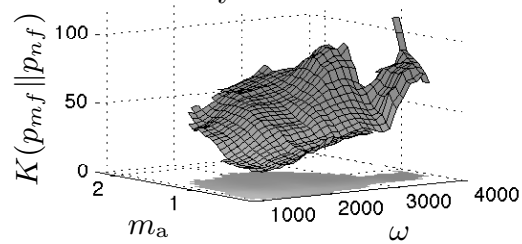

Cylinder 3

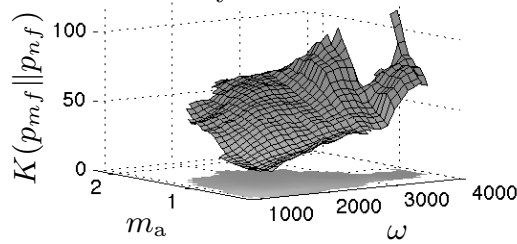

Cylinder 5

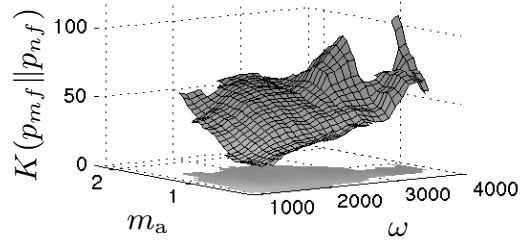

Cylinder 2

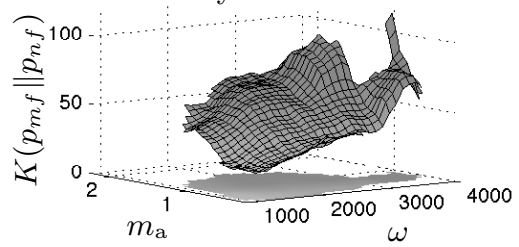

Cylinder 4

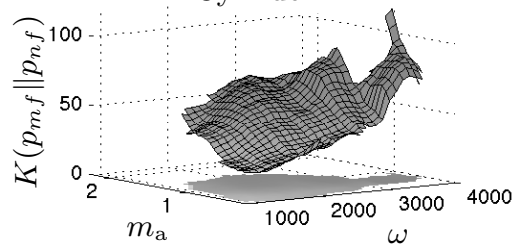

Cylinder 6

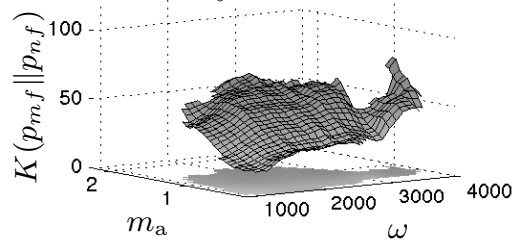

Figure 3.6: Computed Kullback-Leibler divergence of estimated torque data for different speeds $\omega$, loads $m_{\mathrm{a}}$, and cylinders. 



\section{References}

J. Armengol Llobet, A. Bregon, T. Escobet, E. R. Gelso, M. Krysander, M. Nyberg, X. Olive, B. Pulido, and L. Travé-Massuyès. Minimal structurally overdetermined sets for residual generation: A comparison of alternative approaches. In Proceedings of IFAC Safeprocess'09, Barcelona, Spain, 2009.

J. Auzins, H. Johansson, and J. Nytomt. Ion-gap sense in misfire detection, knock and engine control. SAE Technical Paper, 1995.

M. Basseville. On fault detectability and isolability. European Journal of Control, $7(6): 625-637,2001$.

M. Basseville and I. V. Nikiforov. Detection of abrupt changes: theory and application. Prentice-Hall, Inc., Upper Saddle River, NJ, USA, 1993.

A. C. Bittencourt, K. Saarinen, S. Sander-Tavallaey, S. Gunnarsson, and M. Norrlöf. A data-driven approach to diagnostics of repetitive processes in the distribution domain-applications to gearbox diagnostics in industrial robots and rotating machines. Mechatronics, 24(8):1032-1041, 2014.

M. Blanke, M. Kinnaert, J. Lunze, M. Staroswiecki, and J. Schröder. Diagnosis and Fault-Tolerant Control. Springer-Verlag New York, Inc., Secaucus, NJ, USA, 2006.

G. Casella and R. L. Berger. Statistical Inference. Duxbury Resource Center, Pacific Grove, CA, 2001.

J. Chang, M. Kim, and K. Min. Detection of misfire and knock in spark ignition engines by wavelet transform of engine block vibration signals. Measurement Science and Technology, 13(7):1108, 2002. 
C. J. Chen and R. J. Patton. Robust Model-Based Fault Diagnosis For Dynamic Systems. Kluwer International Series on Asian Studies in Computer and Information Science, 3. Kluwer, 1999.

J. Chen and R. J. Patton. Optimal filtering and robust fault diagnosis of stochastic systems with unknown disturbances. IEEE Proceedings of Control Theory and Applications, 143(1):31 -36, 1996.

R. H. Chen, D. L. Mingori, and J. L. Speyer. Optimal stochastic fault detection filter. Automatica, 39(3):377-390, 2003.

T. Chen and M. Adams. A sequential failure detection technique and its application. IEEE Transactions on Automatic Control, 21(5):750-757, 1976.

W. Chen, S. X. Ding, A. H. A. Sari, A. Naik, A. Q. Khan, and S. Yin. Observerbased schemes FDI for wind turbine benchmark. In Proceedings of IFAC World Congress, Milano, Italy, 2011.

C. Commault, J. M. Dion, and S. Y. Agha. Structural analysis for the sensor location problem in fault detection and isolation. Automatica, 44(8):2074$2080,2008$.

F. T. Connolly and G. Rizzoni. Real time estimation of engine torque for the detection of engine misfires. Journal of Dynamic Systems, Measurement, and Control, 116(4):675-686, 1994.

M. O. Cordier, P. Dague, F. Levy, J. Montmain, M. Staroswiecki, and L. TravéMassuyès. Conflicts versus analytical redundancy relations: a comparative analysis of the model based diagnosis approach from the artificial intelligence and automatic control perspectives. IEEE Transactions on Systems, Man, and Cybernetics, Part B: Cybernetics, 34(5):2163 -2177, oct 2004.

Y. Cui, J. Shi, and Z. Wang. System-level operational diagnosability analysis in quasi real-time fault diagnosis: The probabilistic approach. Journal of Process Control, 24(9):1444-1453, 2014.

M. Daigle, I. Roychoudhury, and A. Bregon. Qualitative event-based diagnosis with possible conflicts: Case study on the fourth international diagnostic competition. In Proceedings of the 24th international workshop on principles of diagnosis, Jerusalem, Israel, 2013.

J. de Kleer. Hitting set algorithms for model-based diagnosis. In Proceedings of 22nd International Workshop on Principles of Diagnosis (DX-11), Murnau, Germany, 2011.

J. de Kleer and B. C. Williams. Diagnosing Multiple Faults. Artificial Intelligence, 32(1):97-130, 1987.

S. X. Ding. Model-based fault diagnosis techniques: design schemes, algorithms, and tools. Springer Science \& Business Media, 2008. 
S. Eguchi and J. Copas. Interpreting Kullback-Leibler divergence with the Neyman-Pearson lemma. Journal of Multivariate Analysis, 97:2034-2040, October 2006.

A. Emami-Naeini, M. M. Akhter, and S. M. Rock. Effect of model uncertainty on failure detection: the threshold selector. IEEE Transactions on Automatic Control, 33(12):1106 -1115, dec. 1988.

D. Eriksson, M. Krysander, and E. Frisk. Quantitative stochastic fault diagnosability analysis. In Proceedings of 50th IEEE Conference on Decision and Control, Orlando, Florida, USA, 2011a.

D. Eriksson, M. Krysander, and E. Frisk. Quantitative fault diagnosability performance of linear dynamic descriptor models. In Proceedings of 22nd International Workshop on Principles of Diagnosis (DX-11), Murnau, Germany, 2011b.

D. Eriksson, E. Frisk, and M. Krysander. A sequential test selection algorithm for fault isolation. In Proceedings of 10th European Workshop on Advanced Control and Diagnosis, Copenhagen, Denmark, 2012a.

D. Eriksson, M. Krysander, and E. Frisk. Using quantitative diagnosability analysis for optimal sensor placement. In Proceedings of IFAC Safeprocess, Mexico City, Mexico, 2012b.

Q. Fan, J. Bian, H. Lu, S. Tong, and L. Li. Misfire detection and re-ignition control by ion current signal feedback during cold start in two-stage directinjection engines. International Journal of Engine Research, 15(1):37-47, 2014 .

A. Feldman and A. van Gemund. A two-step hierarchical algorithm for modelbased diagnosis. In Proceedings of the 21st national conference on Artificial intelligence - Volume 1. AAAI Press, 2006.

E. Frisk, M. Krysander, and J. Åslund. Sensor placement for fault isolation in linear differential-algebraic systems. Automatica, 45(2):364-371, 2009.

J. Gertler. Analytical redundancy methods in fault detection and isolation. In Proceedings of IFAC Fault Detection, Supervision and Safety for Technical Processes, Baden-Baden, Germany, 1991.

J. Gertler. Fault Detection and Diagnosis in Engineering Systems. Marcel Dekker Inc., Upper Saddle River, NJ, USA, 1998.

F. Hamelin and D. Sauter. Robust fault detection in uncertain dynamic systems. Automatica, 36(11):1747-1754, 2000.

W. Hamscher, L. Console, and J. de Kleer, editors. Readings in Model-based Diagnosis. Morgan Kaufmann Publishers Inc., San Francisco, CA, USA, 1992. 
F. Harrou, L. Fillatre, and I. Nikiforov. Anomaly detection/detectability for a linear model with a bounded nuisance parameter. Annual Reviews in Control, $38(1): 32-44,2014$.

J. B. Heywood. Internal combustion engine fundamentals. McGraw-Hill series in mechanical engineering. McGraw-Hill, 1988.

J. Huber, H. Kopecek, and M. Hofbaur. Sensor selection for fault parameter identification applied to an internal combustion engine. In Proceedings of IEEE Conference on Control Applications (CCA), Juan Les Antibes, France, 2014. IEEE.

A. Ingimundarson, J. M. Bravo, V. Puig, T. Alamo, and P. Guerra. Robust fault detection using zonotope-based set-membership consistency test. International journal of adaptive control and signal processing, 23(4):311-330, 2009.

R. Isermann. Fault-Diagnosis Systems: An Introduction from Fault Detection to Fault Tolerance. Springer, 2005.

R. Isermann and P. Balle. Trends in the application of model-based fault detection and diagnosis of technical processes. Control engineering practice, 5 (5):709-719, 1997.

C. Jauberthie, N. Verdière, and L. Travé-Massuyès. Fault detection and identification relying on set-membership identifiability. Annual Reviews in Control, 37(1):129-136, 2013.

S. M. Kay. Fundamentals of statistical signal processing: Detection theory. Prentice-Hall, Inc., Upper Saddle River, NJ, USA, 1998.

H. Khorasgani, D. Eriksson, G. Biswas, E. Frisk, and M. Krysander. Robust residual selection for fault detection. In Proceedings of 53rd IEEE Conference on Decision and Control, Los Angeles, USA, 2014.

U. Kiencke. Engine misfire detection. Control Engineering Practice, 7(2):203208, 1999.

M. Kinnaert and J. Hao. Distributed sensor fault detection and isolation over network. In Proceedings of the 2014 IFAC World Congress, Cape Town, South Africa, 2014.

M. Kinnaert, M. Nyberg, and M. Basseville. Discussion on: On fault detectability and isolability by m. basseville. European Journal of Control, 7(6):638-641, 2001.

M. Krysander. Design and Analysis of Diagnosis Systems Using Structural Methods. PhD thesis, Linköpings universitet, June 2006.

M. Krysander and E. Frisk. Sensor placement for fault diagnosis. IEEE Transactions on Systems, Man, and Cybernetics - Part A: Systems and Humans, 38(6):1398-1410, 2008. 
M. Krysander and M. Nyberg. Statistical properties and design criterions for fault isolation in noisy systems. In Proceedings of 19 th International Workshop on Principles of Diagnosis (DX-08), Sydney, Australia, 2008.

M. Krysander, J. Åslund, and M. Nyberg. An efficient algorithm for finding minimal over-constrained sub-systems for model-based diagnosis. IEEE Transactions on Systems, Man, and Cybernetics - Part A: Systems and Humans, $38(1), 2008$.

M. Krysander, F. Heintz, J. Roll, and E. Frisk. FlexDx: A reconfigurable diagnosis framework. Engineering Applications of Artificial Intelligence, 23 (8):1303-1313, October 2010.

S. Kullback and R. A. Leibler. On Information and Sufficiency. Ann. Math. Statist., 22(1):79-86, 1951.

D. Lundström and S. Schagerberg. Misfire Detection for Prechamber SI Engines Using Ion-Sensing and Rotational Speed Measurements. SAE Technical Paper 2001-01-0993, 2001.

J Mohammadpour, M Franchek, and K Grigoriadis. A survey on diagnostic methods for automotive engines. International Journal of Engine Research, $13(1): 41-64,2012$.

J. Molinar-Monterrubio and R. Castro-Linares. Sliding Mode Observer for Internal Combustion Engine Misfire Detection. In Proceedings of Electronics, Robotics and Automotive Mechanics Conference, Cuernavaca, Morelos, Mexico, 2007.

P. J. Mosterman and G. Biswas. Diagnosis of continuous valued systems in transient operating regions. IEEE Transactions on Systems, Man and Cybernetics, Part A: Systems and Humans, 29(6):554-565, 1999.

S. Naik. Advanced misfire detection using adaptive signal processing. International Journal of Adaptive Control and Signal Processing, 18(2):181-198, 2004 .

M. Nyberg. Criterions for detectability and strong detectability of faults in linear systems. International Journal of Control, 75(7):490-501, May 2002.

A. W. Osburn, T. M. Kostek, and M. A. Franchek. Residual generation and statistical pattern recognition for engine misfire diagnostics. Mechanical Systems and Signal Processing, 20(8):2232 - 2258, 2006.

E. S. Page. Continuous inspection schemes. Biometrika, pages 100-115, 1954.

R. J. Patton, P. M. Frank, and R. N. Clark. Issues of Fault Diagnosis for Dynamic Systems. Springer Publishing Company, Incorporated, 1st edition, 2010. 
B. Pulido and C. A. González. Possible conflicts: a compilation technique for consistency-based diagnosis. IEEE Transactions on Systems, Man, and Cybernetics, Part B: Cybernetics, 34(5):2192-2206, 2004.

S. J. Qin. Survey on data-driven industrial process monitoring and diagnosis. Annual Reviews in Control, 36(2):220 - 234, 2012.

R. Raghuraj, M. Bhushan, and R. Rengaswamy. Locating sensors in complex chemical plants based on fault diagnostic observability criteria. AIChE Journal, $45(2): 310-322,1999$.

R. Reiter. A theory of diagnosis from first principles. Artificial Intelligence, 32 (1):57-95, April 1987.

A. Rosich. Sensor placement for fault detection and isolation based on structural models. In Proceedings of 8th IFAC Symposium on Fault Detection, Supervision and Safety of Technical Process, Safeprocess'12, Mexico City, Mexico, 2012.

A. Rosich, E. Frisk, J. Aslund, R. Sarrate, and F. Nejjari. Fault diagnosis based on causal computations. IEEE Transactions on Systems, Man and Cybernetics, Part A: Systems and Humans, 42(2):371 -381, March 2012.

A. Sharma, V. Sugumaran, and S.B. Devasenapati. Misfire detection in an IC engine using vibration signal and decision tree algorithms. Measurement, 50 (0):370 - 380, 2014 .

M. Staroswiecki and G. Comtet-Varga. Analytical redundancy relations for fault detection and isolation in algebraic dynamic systems. Automatica, 37(5):687 699, 2001.

V. Sugumaran, K. I. Ramachandran, and S. B. Devasenapati. Misfire detection in a spark ignition engine using support vector machines. International Journal of Computer Applications, 5(6):25-29, August 2010. Published By Foundation of Computer Science.

C. Svärd. Methods for Automated Design of Fault Detection and Isolation Systems with Automotive Applications. PhD thesis, Linköping University, 2012.

C. Svärd, M. Nyberg, E. Frisk, and M. Krysander. Data-driven and adaptive statistical residual evaluation for fault detection with an automotive application. Mechanical systems and signal processing, 45(1):170-192, 2014.

M. Tamura, H. Saito, Y. Murata, K. Kokubu, and S. Morimoto. Misfire detection on internal combustion engines using exhaust gas temperature with low sampling rate. Applied Thermal Engineering, 31(17):4125-4131, 2011.

F. V. Tinaut, A. Melgar, Laget H., and J. I. Domínguez. Misfire and compression fault detection through the energy model. Mechanical Systems and Signal Processing, 21(3):1521 - 1535, 2007. 
L. Travé-Massuyès. Bridging control and artificial intelligence theories for diagnosis: A survey. Engineering Applications of Artificial Intelligence, 27: $1-16,2014$.

L. Travé-Massuyès, T. Escobet, and X. Olive. Diagnosability Analysis Based on Component-Supported Analytical Redundancy Relations. IEEE Transactions on Systems, Man and Cybernetics, Part A: Systems and Humans, 36(6):1146 -1160 , nov 2006.

V. Venkatasubramanian, R. Rengaswamy, K. Yin, and S. N. Kavuri. A review of process fault detection and diagnosis: Part i: Quantitative model-based methods. Computers \& chemical engineering, 27(3):293-311, 2003a.

V. Venkatasubramanian, R. Rengaswamy, K. Yin, and S. N. Kavuri. A review of process fault detection and diagnosis: Part ii: Qualitative models and search strategies. Computers \&6 Chemical Engineering, 27(3):313-326, 2003b.

V. Venkatasubramanian, R. Rengaswamy, K. Yin, and S. N. Kavuri. A review of process fault detection and diagnosis: Part III: Process history based methods. Computers and Chemical Engineering, 27(3):327 - 346, 2003c.

A. Walter, U. Kiencke, S. Jones, and T. Winkler. Misfire Detection for Vehicles with Dual Mass Flywheel (DMF) Based on Reconstructed Engine Torque. SAE Technical Paper 200\%-01-3544, 2007.

E. Weißenborn, T. Bossmeyer, and T. Bertram. Adaptation of a zero-dimensional cylinder pressure model for diesel engines using the crankshaft rotational speed. Mechanical Systems and Signal Processing, 25(6):1887-1910, 2011.

T. J. Wheeler. Probabilistic Performance Analysis of Fault Diagnosis Schemes. PhD thesis, University of California, Berkeley, 2011.

J. Williams. An overview of misfiring cylinder engine diagnostic techniques based on crankshaft angular velocity measurements. SAE Technical Paper, 1996.

A. Willsky and H. Jones. A generalized likelihood ratio approach to the detection and estimation of jumps in linear systems. IEEE Transactions on Automatic Control, 21(1):108 - 112, feb 1976.

J. Zeng, U. Kruger, J. Geluk, X. Wang, and L. Xie. Detecting abnormal situations using the kullback-leibler divergence. Automatica, 50(11):2777-2786, 2014. 

Papers 



\section{Papers}

The articles associated with this thesis have been removed for copyright reasons. For more details about these see:

http://urn.kb.se/resolve?urn=urn:nbn:se:liu:diva-117058 

Linköping studies in science and technology. Dissertations.

Division of Vehicular Systems

Department of Electrical Engineering

Linköping University

No. 1 Magnus Pettersson, Driveline Modeling and Control, 1997

No. 2 Lars Eriksson, Spark Advance Modeling and Control, 1999

No. 3 Mattias Nyberg, Model Based Fault Diagnosis: Methods, Theory, and Automotive Engine Applications, 1999

No. 4 Erik Frisk, Residual Generation for Fault Diagnosis, 2001

No. 5 Per Andersson, Air Charge Estimation in Turbocharged Spark Ignition Engines, 2005

No. 6 Mattias Krysander, Design and Analysis of Diagnosis Systems Using Structural Methods, 2006

No. 7 Jonas Biteus, Fault Isolation in Distributed Embedded Systems, 2007

No. 8 Ylva Nilsson, Modelling for Fuel Optimal Control of a Variable Compression Engine, 2007

No. 9 Markus Klein, Single-Zone Cylinder Pressure Modeling and Estimation for Heat Release Analysis of SI Engines, 2007

No. 10 Anders Fröberg, Efficient Simulation and Optimal Control for Vehicle Propulsion, 2008

No. 11 Per Öberg, A DAE Formulation for Multi-Zone Thermodynamic Models and its Application to CVCP Engines, 2009

No. 12 Johan Wahlström, Control of EGR and VGT for Emission Control and Pumping Work Minimization in Diesel Engines, 2009

No. 13 Anna Pernestål, Probabilistic Fault Diagnosis with Automotive Applications, 2009

No. 14 Erik Hellström, Look-ahead Control of Heavy Vehicles, 2010

No. 15 Erik Höckerdal, Model Error Compensation in ODE and DAE Estimators with Automotive Engine Applications, 2011

No. 16 Carl Svärd, Methods for Automated Design of Fault Detection and Isolation Systems with Automotive Applications, 2012.

No. 17 Oskar Leufvén, Modeling for control of centrifugal compressors, 2013.

No. 18 Christofer Sundström, Model Based Vehicle Level Diagnosis for Hybrid Electric Vehicles, 2014. 
No. 19 Andreas Thomasson, Modeling and control of actuators and co-surge in turbocharged engines, 2014.

No. 20 Emil Larsson, Model Based Diagnosis and Supervision of Industrial Gas Turbines, 2014.

No. 21 Andreas Myklebust, Dry Clutch Modeling, Estimation, and Control, 2014.

No. 22 Tomas Nilsson, Optimal Engine Operation in a Multi-Mode CVT Wheel Loader, 2015. 